\title{
Fish connectivity mapping: linking chemical stressors by their mechanisms of action- driven transcriptomic profiles
}

\author{
Rong-Lin Wang ${ }^{1 *}\left(\mathbb{D}\right.$, Adam D. Biales ${ }^{1}$, Natalia Garcia-Reyero², Edward J. Perkins², Daniel L. Villeneuve³ \\ Gerald T. Ankley ${ }^{3}$ and David C. Bencic ${ }^{1}$
}

\begin{abstract}
Background: A very large and rapidly growing collection of transcriptomic profiles in public repositories is potentially of great value to developing data-driven bioinformatics applications for toxicology/ecotoxicology. Modeled on human connectivity mapping (Cmap) in biomedical research, this study was undertaken to investigate the utility of an analogous Cmap approach in ecotoxicology. Over 3500 zebrafish (Danio rerio) and fathead minnow (Pimephales promelas) transcriptomic profiles, each associated with one of several dozen chemical treatment conditions, were compiled into three distinct collections of rank-ordered gene lists (ROGLs) by species and microarray platforms. Individual query signatures, each consisting of multiple gene probes differentially expressed in a chemical condition, were used to interrogate the reference ROGLS.

Results: Informative connections were established at high success rates within species when, as defined by their mechanisms of action (MOAs), both query signatures and ROGLs were associated with the same or similar chemicals. Thus, a simple query signature functioned effectively as an exposure biomarker without need for a time-consuming process of development and validation. More importantly, a large reference database of ROGLs also enabled a query signature to cross-interrogate other chemical conditions with overlapping MOAs, leading to novel groupings and subgroupings of seemingly unrelated chemicals at a finer resolution. This approach confirmed the identities of several estrogenic chemicals, as well as a polycyclic aromatic hydrocarbon and a neuro-toxin, in the largely uncharacterized water samples near several waste water treatment plants, and thus demonstrates its future potential utility in real world applications.
\end{abstract}

Conclusions: The power of Cmap should grow as chemical coverages of ROGLs increase, making it a framework easily scalable in the future. The feasibility of toxicity extrapolation across fish species using Cmap needs more study, however, as more gene expression profiles linked to chemical conditions common to multiple fish species are needed.

Keywords: Fish, Gene expression profiles, Connectivity mapping

\section{Background}

There are an estimated 80,000 chemicals in legal use today, with hundreds more added to the inventory each year [1]. A current lack of toxicological information for most of them poses a serious challenge to safeguarding human health and the environment from potentially harmful exposures. Given that traditional toxicity testing

\footnotetext{
* Correspondence: Wang.Rong-Lin@epa.gov

${ }^{1}$ Exposure Methods \& Measurements Division, National Exposure Research Laboratory, US Environmental Protection Agency, 26 W Martin Luther King Dr., MS 587, Cincinnati, OH 45268, USA

Full list of author information is available at the end of the article
}

of chemicals based on whole animals is resourceintensive, time-consuming, and at times challenging in terms of cross-species and -chemical extrapolation, a general consensus has emerged across the environmental science community that alternative practices are needed for evaluation and management of chemical inventories. In recognition of rapid scientific advancements in "-omics" technologies, robotics, computational chemistry, systems biology, and high performance computing, the US National Academy of Sciences has put forth several reports since the turn of the century [2-5] 
recommending broader utilization of in vitro, in silico, and short term in vivo assays with a greater focus on mechanistic pathways in testing of chemicals and assessing their toxicological risks.

Concurrent with this emerging paradigm of toxicology is the ongoing "big data" revolution across scientific disciplines and technological fields. Accelerated by technical advances, there has been an exponential growth in data generation. In biology, for example, the number of DNA sequence bases in GenBank has increased nearly 300,000 fold over the last 30 years, from 0.7 megabases in 1982 to 187 gigabases in 2015. As of May, 2015, the NCBI GEO (National Center for Biotechnology Information Gene Expression Omnibus) hosted well over 1.4 million gene expression profiles (GEPs), including $\sim 20,000$ for fish, $\sim 70,000$ for rats, and $\sim 700,000$ for humans. Each GEP represents the collective expression states of all genes, as measured by a given microarray, for a sample under study. Many of these GEPs are linked to chemical treatment or other biological conditions of potential relevance to toxicology. These abundant transcriptomic data contain a wealth of information and present opportunities for toxicologists to explore computational assessment of chemical toxicity by a datadriven approach. In contrast to individual studies with a narrowly defined scope and limited data, substantial novel insights may be gained from data mining across a large number of independent studies conducted within the same species or even across species. Yet, to date, there has been little research effort in this area in the field of toxicology.

Connectivity mapping (Cmap) represents an in silico and data-driven approach with potentially broad applications in biomonitoring, chemical exposure assessment, toxicity evaluation and extrapolation across species, and grouping of chemicals. Originally proposed for human biomedical research [6], Cmap connects chemicals and disease based on similarities in transcriptomic profiles, driven largely by the underlying mechanisms of action (MOA). Such similarities are revealed by interrogating a database of rank-ordered gene lists (ROGLs) with a query signature. The ROGLs are generated individually from GEPs of treated samples relative to those of the corresponding controls, based on gene probes sorted by their logarithmic fold-changes (LogFCs), and are inclusive of all gene probes on a given microarray. A query signature, on the other hand, contains only a small number of gene probes differentially expressed under a chemical or biological condition of interest. A nonrandom distribution of gene probes from a query signature on ROGLs suggests a similarity in their transcriptomic profiles, and therefore, a connectivity of the underlying chemical or biological conditions. This Cmap determination of the chemical identity associated with a biological sample is thus analogous to forensic database searches by human or DNA fingerprints. Since its inception, Cmap has made a significant impact on drug discovery research and development [7], and is now becoming part of much more ambitious public effort of profiling cell signatures [8]. A similar data-driven approach for pharmaceutical research has also been launched using commercial platforms [9]. For toxicogenomic research with chemicals, the principle of Cmap is equally applicable: those toxicants sharing the same or similar MOAs should yield comparable transcriptomic profiles, and connect with one another [10-12].

Compared to other computational approaches with similar toxicological applications, Cmap has several advantages. First, it is algorithmically simple. Connectivity between two chemical conditions is established simply based on a non-random distribution of multiple gene probes on ROGLs. Second, the information in each GEP is fully preserved, as there is no statistical filtering with regard to generating ROGLs: the entire set of gene probes in the GEP of a treated sample is ranked from top to bottom by their LogFCs relative to the corresponding control(s). Third, Cmap is easily scalable. As more GEPs become available, ROGLs can be simply added individually to an existing reference database without any restructuring or reanalysis. With more ROGLs in the database, there is a greater coverage of chemicals and biological conditions, so the power and applicability of Cmap also increase. Lastly, Cmap is costeffective and user-flexible. As publicly-available GEPs continue to grow, they can be included in a database to expand chemical coverage. An end user can derive a query signature for a sample/condition of interest from a variety of sources such as literature, microarrays, RTPCRs (reverse transcription polymerase chain reaction), or a public "-omics" data repository.

However, adopting a big data approach such as Cmap for toxicogenomics applications faces many challenges. Unlike human Cmap where GEPs originated from relatively homogeneous cell cultures from a single species, the development of Cmap for fish must take into account data heterogeneity as a result of differences in experimental designs and lab practices among independent studies. Technical factors such as choice of expression profiling platforms (e.g., microarrays vs RNA sequencing) and evolving designs within a platform (e.g., microarrays) may further complicate data integration. Lastly and perhaps most challenging of all, conducting interspecific Cmap introduces further evolutionary complexity.

Interspecific Cmap requires a signature derived from one species to interrogate ROGLs of one or more other species. If successful, this allows the broadest possible inclusion of GEPs available in public repositories, and 
can inform toxicity extrapolation from model to nonmodel species. Interspecific Cmap depends on the conservation of both genomes and transcriptomes. In the presence of such conservation, genome annotations become the most limiting factor for interspecific Cmap. Given these considerations, zebrafish and fathead minnow appear to be the two very suitable fish species for a preliminary test of Cmap across species. As a common biological model with extensive genome-level knowledge, zebrafish is a species of choice for many studies, particularly in developmental biology [13]. As such, zebrafish has the largest number of public GEPs available among all fish species. The fathead minnow, on the other hand, has been the dominant aquatic vertebrate test organism in regulatory toxicity testing for decades [14]. Estimated to have shared a last common ancestor 31 million years ago [15], both the zebrafish and fathead minnow are members of the family Cyprinidae, with well-conserved genomes and transcriptomes [16].

This study was undertaken to explore the applications of Cmap in ecotoxicology. The goals were three-fold. First, Cmap was evaluated for connecting the same chemicals within species. In other words, both a query signature and ROGLs under consideration were selected from a single species and associated with an identical chemical. Second, Cmap was tested on related chemicals of the same MOA class within species, for example, by interrogating ROGLs linked to the natural estrogen $17 \beta$ estradiol (E2) with a signature linked to the synthetic estrogen 17 1 -ethinylestradiol (EE2). If successful, Cmap would not only simplify the development of exposure biomarkers, but also provide an alternative way to characterize the extent of overlap among MOAs of related chemicals and inform as to their relative toxicity. Lastly, based on a small number of chemical conditions shared between species, a preliminary trial of interspecific Cmap was conducted to identify issues critical to a more thorough feasibility study in the future.

\section{Methods}

\section{Chemicals and field water samples}

The data employed in the present study were derived from experiments with a number of chemicals (Table 1). The use or source of these chemicals ranges from pesticides, medicine, industrial chemicals or by products, personal care products, and fossil fuel contaminants. In the context of adverse outcome pathways, these chemicals could be grouped by their molecular initiating events (MIEs) [17]. A MIE is defined here as a molecular interaction between a xenobiotic and a specific biomolecule. Since many of these MIEs involve various receptors and enzymes commonly considered as part of the hypothalamic pituitary gonadal (HPG) axis [18], a large portion of chemicals under this study, for example E2 and EE2, are effectively HPG-active toxicants. Also included, among others, were several pyrethroid insecticides (bifenthrin, permethrin, esfenvalerate, cypermethrin) targeting neuro-transmission, and polycyclic aromatic hydrocarbons (PAHs).

In addition to experiments with individual chemicals, the data also include exposures to field water conditions (Table 1) sampled near several waste water treatment plants (WWTPs). The water samples were characterized for a limited number of chemicals (generally around 140 analytes) by their original investigators using traditional chemical analysis methods. For the purpose of evaluating Cmap performance, only those chemicals both positively identified therein and also present in the data of current study are listed in the table. Almost all of the water samples had detectable concentrations of estrogens and bisphenol A. Some of them also contained PAHs.

\section{Microarray data}

Microarray data for this investigation came from a series of US Environmental Protection Agency (USEPA) studies with zebrafish and fathead minnow [18] and US Army Corps of Engineers (USACE) studies with fathead minnow, as well as a number of datasets downloaded from NCBI GEO as of August 2014 (Table 2, Additional file 1: Table S1). There were a total of 3516 microarrays associated with 55 experimental conditions, as defined by chemical, dose, tissue type, and exposure duration. This dataset encompassed many independent studies carried out over years, with a wide range of differences in their original project objectives, experimental designs, and chemical treatment conditions and measured effects, using three microarray platforms in zebrafish and fathead minnow. Given the complex and heterogeneous nature of this dataset, it is difficult to describe in general terms all underlying experimental protocols. Instead, only a brief overview of this dataset is outlined below. Greater experimental details about various studies have been previously published [16, 18-20], are available from the summaries of individual data series available at NCBI GEO (Additional file 1: Table S1), or will be published elsewhere.

\section{USEPA and USACE studies}

A number of experiments were conducted with chemicals targeting HPG-axis [18] and neuro-transmission of zebrafish and fathead minnow. Over the course of these studies, microarray platforms evolved, leading to multiple platforms being used, including Agilent 013223, 015064, 019161 for zebrafish, and Agilent 019597 and 036574 for fathead minnow. Since these platforms had probes duplicated to various extent by design, only unique probes were considered in their cross-mapping. Agilent 013223 and 015064 shared the same 21495 
Table 1 Chemicals and field mixtures associated with the exposure experiments considered in the current study

\begin{tabular}{|c|c|c|c|}
\hline Chemicals/field mixtures & Use/source & Putative MIE & References \\
\hline 1,4-dimethoxybenzene (DMB) & Ingredient in consumer products & - & - \\
\hline 2,3,7,8-tetrachlorodibenzo-p-dioxin (TCDD) & Industrial byproduct & $\begin{array}{l}\text { aromatic hydrocarbon } \\
\text { (Ah) receptor agonist }\end{array}$ & [48] \\
\hline 2,4-dinitrophenol (DNP) & $\begin{array}{l}\text { Antiseptic agent, pesticide, industrial } \\
\text { chemical }\end{array}$ & $\begin{array}{l}\text { Uncoupling oxidative } \\
\text { phosphorylation }\end{array}$ & - \\
\hline benz(a)anthracene (BAA) & Fossil fuels & $\begin{array}{l}\text { DNA mutagen and Ah } \\
\text { receptor agonist (PAH) }\end{array}$ & [49] \\
\hline perfluorinated chemicals (PFC) & Industrial chemical & - & - \\
\hline tert-Butylhydroquinone (TBHQ) & Ingredient in consumer products & - & - \\
\hline Phenanthrene (PHE) & Fossil fuels & $\begin{array}{l}\text { DNA mutagen and Ah } \\
\text { receptor agonist (PAH) }\end{array}$ & [49] \\
\hline Pyrene (PYR) & Fossil fuels & $\begin{array}{l}\text { DNA mutagen and Ah } \\
\text { receptor agonist (PAH) }\end{array}$ & [49] \\
\hline decabromodiphenyl ether (BDE) & Flame retardant & & - \\
\hline dibenzothiophene (DBT) & Fossil fuels & $\begin{array}{l}\text { DNA mutagen and Ah } \\
\text { receptor agonist (PAH) }\end{array}$ & [49] \\
\hline 17ß-estradiol (E2) & Endogenous estrogen & ER agonist & {$[18]$} \\
\hline Diethylstilbestrol (DES) & medicine & ER agonist & - \\
\hline ethniyl estradiol (EE2) & medicine & ER agonist & [18] \\
\hline fadrozol (FAD) & medicine & CYP19 inhibitor & [18] \\
\hline fipronil (FIP) & insecticide & $\begin{array}{l}\text { GABA receptor } \\
\text { antagonist }\end{array}$ & [18] \\
\hline flutamide (FLU) & medicine & $\begin{array}{l}\text { Androgen receptor } \\
\text { antagonist }\end{array}$ & [18] \\
\hline genistein (GEN) & phytoestrogen & ER and PPAR agonist & {$[50]$} \\
\hline ketochonazole (KET) & medicine & CYP11A/CYP17 inhibitor & [18] \\
\hline trenbolone (TRB) & Beef production & AR agonist & [18] \\
\hline trilostane (TRI) & Veterinary medicine & $3 \beta H S D$ inhibitor & {$[18]$} \\
\hline vinclozolin (VIN) & fungicide & $\begin{array}{l}\text { AR antagonist } \\
\text { (fungicide) }\end{array}$ & [18] \\
\hline prochloraz (PRO) & fungicide & CYP17/19 inhibitor & {$[18]$} \\
\hline muscimol (MUS) & research & GABA receptor agonist & [18] \\
\hline bisphenol A (BPA) & Industrial chemical & ER agonist & {$[51]$} \\
\hline Progesterone (PGST) & Endogenous hormone, medicine & PR agonist & {$[52]$} \\
\hline Dihydrotestosterone (DHT) & Endogenous hormone & AR agonist & [53] \\
\hline Haloperidol (HAL) & medicine & $\begin{array}{l}\text { Dopamine D2 receptor } \\
\text { antagonist }\end{array}$ & [54] \\
\hline Diazepam (DIA) & medicine & $\begin{array}{l}\text { GABA-A receptor } \\
\text { modulator }\end{array}$ & {$[55]$} \\
\hline bifenthrin (BIF) & insecticide & $\begin{array}{l}\text { voltage-gated sodium } \\
\text { channels disruption }\end{array}$ & {$[56]$} \\
\hline cypermethrin (CYP) & insecticide & $\begin{array}{l}\text { voltage-gated sodium } \\
\text { channels disruption }\end{array}$ & {$[56]$} \\
\hline esfenvalerate (ESF) & Insecticide & $\begin{array}{l}\text { voltage-gated sodium } \\
\text { channels disruption }\end{array}$ & {$[56]$} \\
\hline Linuron (LIN) & Herbicide & photosynthesis inhibitor & [57] \\
\hline Terbufos (TER) & Insecticide & $\begin{array}{l}\text { acetylcholine esterase } \\
\text { inhibitor }\end{array}$ & {$[58]$} \\
\hline methylparaben (MPA) & Anti-fungal agent & $\begin{array}{l}\text { Uncoupling oxidative } \\
\text { phosphorylation }\end{array}$ & [59] \\
\hline
\end{tabular}


Table 1 Chemicals and field mixtures associated with the exposure experiments considered in the current study (Continued)

\begin{tabular}{|c|c|c|c|}
\hline permethrin (PER) & Insecticide & $\begin{array}{l}\text { voltage-gated sodium } \\
\text { channels disruption }\end{array}$ & [56] \\
\hline Propanil (PPL) & Herbicide & photosynthesis inhibitor & {$[60]$} \\
\hline azinphos-methyl (APM) & Insecticide & $\begin{array}{l}\text { acetylcholine esterase } \\
\text { inhibitor }\end{array}$ & {$[61]$} \\
\hline Propranolol (PPLL) & Medicine & $\begin{array}{l}\beta \text {-adrenergic receptor } \\
\text { antagonist }\end{array}$ & {$[62]$} \\
\hline protein kinase C inhibitor 412 (PKC412) & Pharmaceutical compound & tyrosine kinase inhibitor & [63] \\
\hline Triclocarban (TCC) & Anti-bacterial agent & - & - \\
\hline Gemfibrozil (GEM) & Medicine & $\begin{array}{l}\text { PPAR binding and } \\
\text { activation }\end{array}$ & [64] \\
\hline cyclotrimethylenetrinitramine (RDX) & Explosive & Neuro-toxin? & - \\
\hline TNT & Explosive & - & - \\
\hline \multicolumn{4}{|l|}{ Water samples near WWTPs } \\
\hline $\begin{array}{l}\text { Effluent; WWTP, San Diego, California (EFFLa, } \\
\text { EFFHa) }\end{array}$ & Positive for GEM, DIA, E2, PGST & - & [29] \\
\hline Effluent; WWTP, Los Angeles, California (EFFHb) & Positive for GEM, PGST & - & [29] \\
\hline Effluent; WWTP, Duluth Minnesota (WLSSD) & Positive for various estrogens, BPA & - & $\begin{array}{l}\text { Unpublished observations } \\
\text { (Jenna Cavallin US EPA) }\end{array}$ \\
\hline $\begin{array}{l}\text { Upstream, effluent, downstream, WWTP, Ely } \\
\text { Minnesota (ElyUS, ElyEFF, ElyDS) }\end{array}$ & $\begin{array}{l}\text { At least one site positive for various } \\
\text { estrogens, BPA, TCC, PAHs, chlorpyrifos }\end{array}$ & - & [30] \\
\hline $\begin{array}{l}\text { Upstream, effluent, downstream, WWTP, } \\
\text { Hutchinson Minnesota (HutUS, HutEFF, HutDS) }\end{array}$ & $\begin{array}{l}\text { At least one site positive for various } \\
\text { estrogens, DES, BPA, TCC, PAHs, } \\
\text { chlorpyrifos }\end{array}$ & - & [30] \\
\hline $\begin{array}{l}\text { Upstream, effluent, downstream, WWTP, } \\
\text { Rochester Minnesota (RochUS, RochEFF, } \\
\text { RochDS) }\end{array}$ & $\begin{array}{l}\text { At least one site positive for various } \\
\text { estrogens, BPA, TCC, }\end{array}$ & - & [30] \\
\hline $\begin{array}{l}\text { storm, stream, waste water; WWTP, Gainesville, } \\
\text { Florida (stormH2O, strH2O, wasteH2O) }\end{array}$ & $\begin{array}{l}\text { wasteH2O seasonally positive for BPA, DIA, } \\
\text { PFCs }\end{array}$ & - & [65] \\
\hline
\end{tabular}

$A R$ androgen receptor, $E R$ estrogen receptor, GABA gamma-aminobutyric acid, HSD hydroxysteroid dehydrogenase, MIE molecular initiating event, $P A H$ polycyclic aromatic hydrocarbons, $P R$ progesterone receptor, PPAR peroxisome proliferators-activated receptor-a, WWTP waste water treatment plant

probes but with different layouts (hereafter referred to as ZF 21K). Agilent 019161 had 43603 probes (ZF $43 \mathrm{~K})$, but only $37 \%$ (16083) of them could be mapped to Agilent 015064. For fathead minnow, Agilent 019597 had 15208 probes (FHM 15K), which formed a subset of 49849 unique probes found in Agilent 036574 (FHM 60K). The experimental conditions in this study for fathead minnow overlapped considerably between these two platforms. In order to keep their ROGLs as a single collection for maximum comparability, only the 15000 common probes were retained. The entire microarray dataset from these studies is available at NCBI-GEO as the accessions GSE38070, GSE60202, GSE70807, and GSE70936.

\section{Animal usage}

Fish were treated humanely, and all laboratory procedures involving animals were reviewed and approved by the USEPA Animal Care and Use Committee in accordance with Animal Welfare Act regulations and Interagency Research Animal Committee guidelines.

\section{Zebrafish experiments}

Reproductively mature zebrafish (ab wild-type strain, 57 months old) were exposed to a continuous flow of sand filtered, UV-sterilized, Lake Superior water (LSW; controls) or test chemicals dissolved in LSW for 24, 48, or $96 \mathrm{~h}$ at the USEPA laboratory in Duluth, MN. At the end of each exposure period, fish were anesthetized in a buffered solution of tricaine methanesulfonate (MS-222; Finquel, Argent, Redmond WA, USA) and various tissues were collected and shipped overnight on dry ice to the USEPA laboratory in Cincinnati, OH. Total RNA isolated from selected tissue samples was then sent to Cogenics Corporation, an Agilent certified contract laboratory (Morrisville, North Carolina 27560, USA). Hybridization was conducted using a two-color protocol on ZF $15 \mathrm{~K}$ and ZF 43K microarrays (Agilent Technologies, Santa Clara, CA, USA), followed by high-resolution 
Table 2 A summary of 3516 microarray samples and their chemical treatment conditions

\begin{tabular}{|c|c|}
\hline $\begin{array}{l}\text { Zebrafish microarray design, sample size, and } \\
\text { chemicals }\end{array}$ & Fathead minnow microarray design, sample size, and chemicals \\
\hline ZF 21K (Agilent 013223, 15064): USEPA (290) & FHM 15K (Agilent 019597,_036574): USEPA (580) \\
\hline ethniyl estradiol (EE2) ${ }^{a}$ & bifenthrin (BIF) ${ }^{a}$ \\
\hline fadrozol (FAD) $)^{a}$ & cypermethrin (CYP) ${ }^{\mathrm{a}}$ \\
\hline fipronil $(F I P)^{a}$ & permethrin (PER) ${ }^{\mathrm{a}}$ \\
\hline flutamide $(\mathbf{F L U})^{\mathrm{a}}$ & esfenvalerate (ESF) \\
\hline ketochonazole $(K E T)^{a}$ & $\mathrm{EE} 2^{\mathrm{a}}$ \\
\hline muscimol (MUS) $)^{a}$ & Terbufos (TER) ${ }^{a}$ \\
\hline \multicolumn{2}{|l|}{ prochloraz (PRO) $)^{\text {a }}$} \\
\hline trenbolone $(\mathrm{TRB})^{\mathrm{a}}$ & FHM 15K (Agilent 019597): USACE (1711) \\
\hline trilostane $(\mathrm{TRI})^{\mathrm{a}}$ & BPA \\
\hline \multirow[t]{2}{*}{ vinclozolin $(\mathrm{VIN})^{\mathrm{a}}$} & $F A D^{a}$ \\
\hline & $F L U^{a}$ \\
\hline ZF 21K (Agilent 013223, 15064): NCBI (154) & Gemfibrozil (GEM) ${ }^{\mathrm{a}}$ \\
\hline tert-Butylhydroquinone (TBHQ) ${ }^{a}$ & $\mathrm{KET}^{\mathrm{a}}$ \\
\hline 2,3,7,8-tetrachlorodibenzo-p-dioxin (TCDD) ${ }^{\mathrm{a}}$ & KET_TNT_KET \\
\hline oxygen $(\mathrm{O} 2)^{\mathrm{a}}$ & KET_TNT_TNT \\
\hline 2,4-dinitrophenol (DNP) & PRO \\
\hline 1,4-dimethoxybenzene (DMB) & RDX \\
\hline azinphos-methyl (APM) ${ }^{a}$ & Effluent of Western Lake Superior Sanitary District (WLSSD) \\
\hline \multirow[t]{2}{*}{ Haloperidol (HAL) } & TRB $^{\mathrm{a}}$ \\
\hline & TRB_BPA_TRB_BPA \\
\hline ZF 43K (Agilent 019161): USEPA (24) & TRB_BPA_BPA \\
\hline$F L U^{a}$ & TRB_BPA_TRB \\
\hline \multirow[t]{2}{*}{$\mathrm{PRO}^{\mathrm{a}}$} & TRB_EE2_EE2 \\
\hline & TRB_EE2_TRB \\
\hline ZF 43K (Agilent 019161): NCBI (270) & TRB_EE2_TRB_EE2 \\
\hline benz(a)anthracene (BAA) ${ }^{a}$ & TRB_TCC_TCC (triclocarban) \\
\hline decabromodiphenyl ether (BDE) ${ }^{a}$ & TRB_TCC_TRB \\
\hline bisphenol A (BPA) ${ }^{\mathrm{a}}$ & TRB_TCC_TRB_TCC \\
\hline dibenzothiophene (DBT) & $\mathrm{TRI}^{\mathrm{a}}$ \\
\hline Diazepam (DIA $)^{a}$ & VIN ${ }^{a}$ \\
\hline \multicolumn{2}{|l|}{ 17ß-estradiol (E2) ${ }^{\mathrm{a}}$} \\
\hline$E 2^{a}$ & FHM 15K (Agilent 019597_036574): NCBI (487) \\
\hline$E E 2^{a}$ & Diethylstilbestrol (DES) $)^{a}$ \\
\hline FLU & Dihydrotestosterone (DHT) \\
\hline genistein $(\mathbf{G E N})^{\mathrm{a}}$ & $E 2^{\mathrm{a}}$ \\
\hline Linuron $(\mathrm{LIN})^{\mathrm{a}}$ & $\begin{array}{l}\text { Field exposure (EFFLa, EFFHaa; effluent, WWTP San Diego; EFFHba ; effluent, WWTP Los } \\
\text { Angeles) }\end{array}$ \\
\hline methylparaben (MPA) ${ }^{a}$ & Field exposure (surface, stream, waste water ${ }^{a}$ ) \\
\hline protein kinase C inhibitor $412\left(\right.$ PKC412) ${ }^{a}$ & 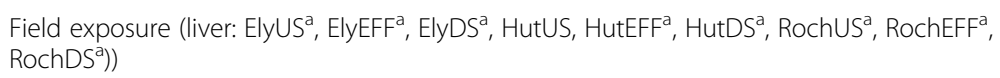 \\
\hline Propanil (PPL) ${ }^{a}$ & Field exposure (ovary: ELYeff, ELYds, HUTeff, HUTds, ROCHds, ROCHeff) \\
\hline $\mathrm{PRO}^{\mathrm{a}}$ & FLU \\
\hline Pyrene (PYR) & Linuron \\
\hline
\end{tabular}


Table 2 A summary of 3516 microarray samples and their chemical treatment conditions (Continued)

\begin{tabular}{ll}
\hline cyclotrimethylenetrinitramine $(\mathrm{RDX})^{\mathrm{a}}$ & perflorinated chemicals (PFC) \\
& Phenanthrene (PHE) \\
& Progesterone (PGST) \\
& Propranolol (PPLL) \\
RDX
\end{tabular}

Zebrafish: ZF 21K (Agilent 013223, 21495 probes unique; Agilent 015064, 21495 probes), ZF 43K (Agilent 019161,43603 probes unique). Fathead minnow: FHM 15K (Agilent 019597, 15208 unique probes; Agilent 036574, 15208 of 49849 unique probes). Chemicals with at least one experiment condition (different exposure durations either in single or combinations) with DEGs $\geq 4$ are marked by "a", and those shared across platforms or species are highlighted once in bold

scanning and image processing by Agilent Feature Extraction software.

\section{Fathead minnow experiments}

Fish exposures were conducted in the USEPA laboratories in Duluth, MN and Cincinnati, OH; and the USACE laboratories in Vicksburg, MS. For exposures to HPGactive toxicants, reproductively mature fathead minnows (5-7 months old) were tested using LSW as the control and carrier of the test chemicals. All exposures conducted at EPA Duluth laboratories were continuous, flow-through experiments. Representative experimental designs for these experiments are detailed elsewhere [18-20]. Exposures to pyrethroids were conducted in Cincinnati. Fathead minnow fry (48 hours post hatch) and adults (5-7 months old) were exposed to the selected chemicals for 24,48 , or 72 hours in a static or flow-through system. Exposures to TNT, RDX, and mixture of TNT and KET were conducted at USACE Vicksburg laboratories under static renewal conditions using adult fathead minnow (5-7 months old) that will be described elsewhere. At the end of each exposure period, whole fry or tissues from adult fish used for transcriptomic analyses were snap-frozen in liquid nitrogen and stored at $-80^{\circ} \mathrm{C}$ until RNA was extracted, using either Qiagen RNeasy mini kits (Qiagen, Valencia, CA, USA) or Tri-Reagent (Sigma, St. Louis, MO, USA). Expression profiling was carried out using a single-color protocol on either a FHM 15K (GEO accession GPL9248, designed by Dr. Nancy Denslow, University of Florida, Gainesville, FL, USA) or a FHM 60K microarray (GPL17098, designed by Dr. Natalia Garcia-Reyero) [21], in the Environmental Laboratory of the US Army Engineer Research and Development Center in Vicksburg, MS (1711 arrays) or in EPA Cincinnati (580 arrays). One hundred to $1000 \mathrm{ng}$ of total RNA was used for all hybridizations. Probe labeling, amplification, and hybridization were performed using Agilent Quick Amp Labeling Kit following the manufacturer's One-Color Microarray Hybridization Protocol. Microarrays were scanned with a high-resolution scanner and the images were processed with Agilent Feature Extraction software.

\section{Public data from NCBI GEO}

A total of 911 text output files from Agilent Feature Extraction software, representing 33 GEO data series sharing a common microarray platform with those of the USEPA and USACE studies as described above, were assembled and curated (Additional file 1: Table S1). Each sample file was annotated according to chemical exposure, dose, tissue type, and exposure duration.

\section{Cmap development and analysis}

Fish Cmap consists of three components: construction of query signatures from microarray samples of chemical and biological interest, construction of a reference database of ROGLs tagged with chemical or biological conditions, and computational query of the database using the prepared signatures. Each of the three components is outlined below.

\section{Query signatures}

A query signature for a treatment condition contained multiple differentially expressed gene probes (DEGs) relative to an appropriate control. The DEGs were determined by a modified $t$-test implemented in the $\mathrm{R}$ package limma [22]. A number of $\mathrm{R}$ scripts [23] were developed for this purpose to accommodate different microarray designs such as one-color, two-color direct comparison of treatment and control, two-color with a common reference, and two-color with dye-swaps. Greater detail about DEG determination is available elsewhere [16]. The number of top DEGs selected as a signature and ranked by false discovery rate depended on the types of Cmap query. The Cmap query minimum was lowered from the recommended value of 10 [24], to four DEGs in order to encompass more experimental conditions. On average, though, a signature contained 57 to 88 DEGs for queries made within platforms/species, and 110 to 181 DEGs for Cmap across platforms/ species. Intuitively, a larger number of DEGs per signature in the latter case might help to compensate for the possible inconsistencies in GEPs from different microarray platforms within a species, and the possible divergence of chemical MOAs across species. Each DEG in a signature was accompanied by its own value of 
logarithmic fold-change. In total, 109 unique signatures were prepared for within-platform queries and 61 signatures for queries across platforms/species (Additional file 2: Table S2). These signatures were named after fish sample treatment conditions by the order of chemical, dose, gender, tissue, and exposure duration.

\section{ROGLS}

A ROGL of a treated sample was prepared from appropriate GEPs in several ways depending on study design. For one-color data, gene probe intensities of each treated sample were compared to the corresponding average intensities derived from its specific group of control samples. As a result, each gene probe was given a $\operatorname{LogFC}$ of treated over control. Gene probes were then sorted by the absolute values of their LogFC from the smallest to the greatest, and assigned either a positive or negative rank from 1 to $\mathrm{N}$ based on the signs of LogFC, with $\mathrm{N}$ being number of probes in a given microarray. For two-color direct comparison of a pair of treated over control samples on the same microarray, a ROGL was generated similarly for the treated but within the pair only. For two-color with a common reference design, gene probe intensities of each treated sample were again compared to those averaged over the corresponding reference group. In total, there were 2387 ROGLs in the constructed fish reference database: 386, 203, and 1798 respectively for ZF $21 \mathrm{~K}$, ZF $43 \mathrm{~K}$, and FHM $15 \mathrm{~K}$. For maximum flexibility, the ROGLs from these three platforms were maintained as three distinct collections. Cmap across-platform or across-species was implemented by substituting the probe identifications (IDs) from a source query signature with their equivalent/ orthologous probe IDs in its target platform or species.

\section{Cmap}

Interrogation of the fish reference database was conducted using software sscMap [24], containing an algorithm based on the principles of the original Cmap [6]. Basically, Cmap measures the strength of connectivity between a query signature and a ROGL by a connectivity score of their summed ranks. To assess its associated pvalue, the default value of 10,000 simulated signatures, each containing the same number of gene probes as the original query signature, are randomly generated from the ROGL. From them connectivity scores are calculated. The p-value for the original query is the proportion of simulated query signatures with their connectivity scores greater than or equal to the observed score. In practice, related ROGLs are typically organized by sscMap into various sets, each defined by some common experimental parameters such as chemical, dosage, and tissue types, and then interrogated by query signatures. Both connectivity score and p-value are slightly modified to account for the variation in the size of individual ROGL sets. With a parameter $\mathrm{S}$ denoting the number of ROGL sets contained in a database collection and interrogated by a query signature, the number of false connections was controlled by a critical p-value of $1 / \mathrm{S}$. Each signature was set as "unordered" in the analysis so all up-regulated genes had the same weight of +1 , and down-regulated genes had a weight of -1 in contributing to the connectivity score. The highestscored, statistically significant, and unique pairs of signature-ROGL (excluding those originated from the same experiment) were identified across queries within each platform, and visualized in Cytoscape [25].

To fully evaluate the effectiveness of Cmap, query signatures and ROGLs were arranged into three configurations: within the same platforms and species, across zebrafish platforms, and across species. Because of the differences in coverage of chemicals and their varying transcriptomic impact as measured by the number of DEGs/average LogFC among treatment conditions, queries across platforms and across species were conducted in both directions in order to identify all potential chemical-chemical connections. To enable queries across platforms and species, however, their corresponding probes or orthologs had to be mapped first. This was implemented through several successive steps of ID mapping among ZF $21 \mathrm{~K}, \mathrm{ZF} 43 \mathrm{~K}$, and FHM $15 \mathrm{~K}$ microarrays. For example, to identify orthologs between FHM $15 \mathrm{~K}$ and ZF $21 \mathrm{~K}$, the probe sequences from FHM $15 \mathrm{~K}$ were mapped to their corresponding fathead minnow EST (Expressed Sequence Tag) target sequences (courtesy of Dr. Nancy Denslow, University of Florida) first by TBLASTX. These EST sequences were then mapped to the NCBI nucleotide (NT, as of July, 2013) and protein (NR, as of July 2013) databases by TBLASTX and BLASTX respectively, effectively associating fathead minnow probe IDs to their corresponding NCBI accession IDs. With their greater sequence length, ESTs are presumably more likely than shorter probe sequences to capture orthologs across species. All three rounds of BLAST mapping had a minimum E-value cutoff of $\mathrm{E}^{-06}$. These fathead minnow IDs were then joined to a variety of zebrafish accession IDs prepared by the NCBI [26], and finally to Agilent probe annotations [27]. In the end, a total of 9304 probes (43\%) from ZF $21 \mathrm{~K}$ were linked to 6899 probes (45 \%) from FHM 15K through 6573 common Entrez GeneIDs in NCBI. Similarly, 16376 probes (38 \%) from ZF 43K were mapped to 9861 probes (65\%) of FHM 15K based on a common set of 10353 Entrez GeneIDs. In addition, 13273 probes (62 \%) from ZF $21 \mathrm{~K}$ mapped to 16083 probes (37 \%) of ZF 43K were 
based entirely on the NCBI "gene2accession" file without using any BLAST programs.

\section{Results}

The performance of Cmap was evaluated by examining the ROGL hits with connectivity scores ranked highest either by individual query signatures or across signatures, based on fish samples profiled on each of the three microarray platforms: ZF $21 \mathrm{~K}$, ZF 43K, and FHM $15 \mathrm{~K}$. The primary purpose of examining queries individually was to evaluate whether a query signature can indeed connect with its intended ROGL targets when they had commonly associated chemical conditions. This evaluation was carried out both within and across microarray platforms, as well as across fish species. These connections essentially establish the chemical identity of a query signature based on the degree to which chemicals involved have shared MOAs. Highscoring pairs of query signature-ROGL across-queries, on the other hand, could reveal additional novel insights about the MOA similarity of related chemicals. For better clarity in their visualization in a chemical network, each connected pair of chemical conditions was treated as directionless, regardless of which node in the pair represented a signature or a set of ROGLs.

\section{Validation of Cmap algorithm}

Overall Cmap performance was variable, as measured by the percentage of query signatures producing informative connections. An informative connection is arbitrarily defined as a signature and one of its top five ROGL hits sharing the same or similar class of chemicals. Cmap was very effective when both query signatures and ROGLs were from the same microarray platform/species (Table 3). The relatively lower performance in fathead minnow was probably because many treatment conditions had no or very few DEGs (Table 2, Additional file 3: Figure S1). When query signatures and ROGLs were from different platforms and species, the gene probe IDs in a query signature had to be cross-mapped to those in the targeted ROGLs. With the configuration of target probe IDs coupled with source LogFC, an average

Table 3 Summary of Cmap by the percentage of query signatures producing informative connections

\begin{tabular}{llll}
\hline Microarray platforms & ZF 21K & ZF 43K & FHM 15K \\
\hline ZF 21K & $35 / 36(97 \%)$ & $11 / 13(85 \%)$ & $4 / 8(50 \%)$ \\
ZF 43K & $6 / 12(50 \%)$ & $36 / 36(100 \%)$ & $5 / 10(50 \%)$ \\
FHM 15K & $6 / 12(50 \%)$ & $5 / 6(83 \%)$ & $35 / 46(76 \%)$ \\
\hline
\end{tabular}

An informative connection was established when a query signature shared the same or similar class of chemicals with at least one of the top five ROGL hits, as ranked by an adjusted connectivity score with a $p$-value $\leq 1 /$ (S sets of ROGLs). All cross-platform/species Cmap were based on target probe IDs + source gene log-fold changes on shared chemical conditions. Only unique query signatures were considered in calculations success rate of $61 \%$ was observed based on a small number of treatment conditions in common across the platforms/species.

A more detailed examination of connectivity between query signatures and ROGLs provided additional insights into the performance of Cmap. As expected, a query signature almost always connected with ROGLs of its originating treatment condition as the best hit when both came from the same platform (Table 4). In many instances, this connectivity of the same or similar class of chemicals extended across independent experiments, different tissue types, and chemical mixtures as well. For example, a signature from the brain tissue of zebrafish treated with EE2 (EE2_30ngL_M_Brain_48hr) connected with the ROGLs of both EE2_testis and EE2_ovary, overriding the strong impact of tissue types typically observed on fish transcriptomes [28]. Significantly, this strong connectivity among chemical treatment conditions based on their shared MOAs was not limited to HPG-active toxicants. Similarly strong connections were observed in chemicals targeting other biological pathways/processes such as neurotransmission (BIF_0.15ugL_larvae_48hr), regulation of xenobiotic metabolism (TCDD_2nM_embryo_6h), signal transduction (PKC412_40ugL_fish_6dpf), and photosynthesis (linuron_1.2mgL_embryo_48hr).

Beyond single chemical exposures, Cmap was also effective in discriminating chemical mixtures. For example, when fish were exposed to a mixture of two different chemicals (Mixture_M_Brain; containing terbufos and permethrin), this mixture had barely detectable effects on gene expression, so no signature could be constructed. Still, its ROGLs were informative, connecting to the signatures of both terbufos and bifenthrin from other independent experiments. Bifenthrin is another pyrethroid insecticide similar to permethrin. Notable was the fact that the bifenthrin signature here originated from whole fish larvae while the ROGLs of terbufos/permethrin mixture came from adult brain tissue. At the concentrations used in the exposure, permethrin had very little effect on gene expression, resulting in a relatively uninformative signature consisting of only six gene probes. As ROGLs, however, permethrin also formed strong connection with terbufos and bifenthrin.

The microarray data from previous studies of water conditions near several municipal WWTPs across the USA provided a "real world" assessment of Cmap performance (Table 5). Several observations were notable. There were considerable similarities among the water conditions near these WWTPs as reflected in their fish ROGLs. These similarities were observed both within locations (e.g., upstream, effluent, downstream) and across geographic locations. Second, there were high agreements between Cmap and chemical analyses from those studies with regard to 
Table 4 Top five significant hits, if any, of selected Cmap queries within microarray platforms

\begin{tabular}{|c|c|c|c|c|c|}
\hline Signatures & 1st match & 2nd match & 3rd match & 4th match & 5th match \\
\hline & \multicolumn{5}{|c|}{ Within ZF 21K (p-value cutoff 1/45=0.022) } \\
\hline EE2_30ngL_Ovary_96hr & Self & FAD_Ovary & TRB_F_Brain & EE2_Testis & FAD_M_Brain \\
\hline EE2_30ngL_M_Brain_48hr & Self & EE2_Testis & FAD_M_Brain & TRB_F_Brain & EE2_Ovary \\
\hline EE2_30ngL_M_Liver_48hr & Self & TRB_F_Liver & EE2_Testis & O2_Testis & KET_M_Liver \\
\hline EE2_30ngL_Testis_48hr & Self & EE2_Ovary & EE2_M_Brain & FIP_F_Brain & TRI_TestisLow \\
\hline FAD_25ugL_F_Brain_48hr & Self & TRB_F_Brain & FAD_M_Brain & FAD_Ovary & EE2_Testis \\
\hline FAD_25ugL_Ovary_96hr & Self & EE2_Ovary & FAD_M_Brain & TRI_TestisLow & TRB_F_Brain \\
\hline FIP_5ugL_Testis_48hr & Self & FIP_Ovary & TRI_Testis & FIP_M_Brain & FLU_Testis \\
\hline FLU_1700ugL_Ovary_48hr & Self & FLU_Testis & PRO_Testis & VIN_Ovary & KET_Ovary \\
\hline MUS_500ugL_F_Brain_48hr & Self & VIN_Ovary & MUS_M_Brain & KET_M_Brain & VIN_Testis \\
\hline MUS_500ugL_M_Brain_48hr & Self & MUS_F_Brain & VIN_Ovary & KET_M_Brain & KET_Ovary \\
\hline O2_1mgL_Testis_4d & Self & O2_Ovary & EE2_M_Liver & O2_Ovary & VIN_Testis \\
\hline PRO_500ugL_F_Brain_48hr & FLU_Testis & self & PRO_Testis & VIN_Ovary & KET_Ovary \\
\hline PRO_500ugL_Ovary_48hr & Self & FLU_Ovary & FLU_Testis & KET_Ovary & PRO_Testis \\
\hline TCDD_2nM_Embryo_6h & Self & TCDD_Embryo & TRI_Ovary & O2_Ovary & PRO_Testis \\
\hline TRI_2500ugL_Testis_24hr & Self & VIN_Testis & VIN_Ovary & KET_Ovary & TRI_TestisLow \\
\hline VIN_1000ugL_Ovary_48hr & Self & KET_Ovary & TRI_Testis & VIN_Testis & FIP_Ovary \\
\hline \multirow[t]{2}{*}{ VIN_1000ugL_Testis_48hr } & Self & FLU_Testis & PRO_Testis & TRI_Testis & VIN_Ovary \\
\hline & \multicolumn{5}{|c|}{ Within ZF 43K ( $p$-value cutoff 1/39=0.026) } \\
\hline BPA_0.01ugL_Ovary_96hr & Self & BPA_Ovary & BPA_Ovary & BPA_Ovary & BPA_Embryo \\
\hline E2_1uM_Embryo_4dpf & self & E2_M_Liver & GEN_Embryo & GEN_Embryo & FLU_Embryo \\
\hline EE2_0.65mgL_Embryo_48hr & EE2_Embryo & EE2_Embryo & GEN_Embryo & PARAB_Embryo & PYR_Embryo \\
\hline E2_5ugL_M_Liver_48hrs & self & E2_Embryo & PARAB_Embryo & PARAB_Embryo & GEN_Embryo \\
\hline GEN_2.4mgL_Embryo_48hr & self & GEN_Embryo & PARAB_Embryo & DBT_Embryo & diazepam_Brain \\
\hline PKC412_40ugL_fish_6dpf & PKC412_fish & self & RDX_fry & diazepam_Brain & RDX_fry \\
\hline PRO_500ugL_F_Brain_48hr & PRO_Ovary & linuron_Embryo & FLU_Ovary & PRO_F_Brain & linuron_Embryo \\
\hline PRO_500ugL_Ovary_48hr & self & FLU_Ovary & linuron_Embryo & PRO_F_Brain & linuron_Embryo \\
\hline RDX_7.5mgL_fry_96hr & self & RDX_fry & RDX_fry & RDX_fry & RDX_fry \\
\hline BPA_8mgL_Embryo_48hr & self & BPA_Embryo & EE2_Embryo & BAA_Embryo & PRO_Embryo \\
\hline diazepam_273ngL_brain_14d & self & diazepam_Brain & PKC412_fish & RDX_fry & RDX_fry \\
\hline linuron_1.2mgL_Embryo_48hr & self & linuron_Embryo & PKC412_fish & BPA_Embryo & diazepam_Brain \\
\hline PARAB_19.8mgL_Embryo_48hr & self & PARAB_Embryo & linuron_Embryo & linuron_Embryo & PYR_Embryo \\
\hline \multirow[t]{2}{*}{ PRO_1.7mgL_Embryo_48hr } & self & PRO_Embryo & E2_Embryo & BPA_Embryo & PARAB_Embryo \\
\hline & \multicolumn{5}{|c|}{ Within FHM 15K ( $p$-value cutoff $1 / 132=0.0076)$} \\
\hline BIF_0.15ugL_Larvae_48hr & BIF_Larvae & self & TER_M_Brain & Mixture_M_Brain & KETTNTKET_Ovary \\
\hline BIF_0.3ugL_Larvae_48hr & self & CYP_Larvae & ESF_Larvae & ESF_Larvae & PER_Larvae \\
\hline CYP_1ugL_Larvae_48hr & self & VZ_Ovary & PER_Larvae & CYP_larva & RDX_Ovary \\
\hline DES_1ngL_Liver_96h & EE2_Liver & self & PHE_High_Liver & E2_X_M_Liver & DES_Liver \\
\hline E2_4ugL_M_Liver_14d & self & E2_M_Liver & EE2_Liver & DES_Liver & ElyEFF_Liver \\
\hline EE2_25ngL_Liver_72h & E2_M_Liver & self & E2_X_M_Liver & DES_Liver & ElyEFF_Liver \\
\hline
\end{tabular}


Table 4 Top five significant hits, if any, of selected Cmap queries within microarray platforms (Continued)

\begin{tabular}{|c|c|c|c|c|c|}
\hline GEM_600ugL_Ovary_8d & self & GEM_Ovary & TrbEE2TrbEE2_Ovary & RochDS_Ovary & TrbEE2TRB_Ovary \\
\hline PHE_High_Liver_48hr & self & PHE_Med_Liver & ElyEFF_Liver & ElyUS_Liver & PFCs_Low_Liver \\
\hline TRB_30ngL_Ovary_24h & self & FLU_Ovary & TrbTCCTCC_Ovary & GEM_Ovary & GEM_Ovary \\
\hline TER_57.5ugL_M_Brain_72h & self & Mixture_M_Brain & PER_M_Brain & BIF_Larvae & KET_Ovary \\
\hline
\end{tabular}

Only signatures connected to multiple conditions are included. Where similar signatures exist for a condition, only one is listed. ROGL hits are ranked by their adjusted connectivity scores and filtered by a p-value cutoff of $1 /$ (number of sets of ROGLs). Informative connections, defined as a signature and one of its top five ROGL hits sharing the same or similar class of chemicals, are highlighted in bold. Self: a query signature and the connected ROGLs originated from the same experiment

the occurrence of known estrogenical chemicals, such as E2 and EE2 [29, 30]. For example, the water samples near WWTPs of San Diego (EFFHa, EFFLa) and Los Angeles (EFFHb), California were both reported to be estrogenpositive [29]. Their estrogenic identities were confirmed by Cmap when they were examined either as query signatures (Table 5) or ROGLs (not shown). Various types of estrogenic chemicals were also found near the WWTPs of Ely, Hutchinson, and Rochester, MN [30]. By Cmap, estrogen-associated ROGLs were also connected to the signatures of these water samples, with connectivity scores ranked at 10th (Ely effluent, Ely downstream), 16th (Ely upstream, Hutchinson effluent), 13th (Hutchinson downstream), 18th (Rochester downstream), 11th (Rochester effluent), and 12th (Rochester upstream). Measured against a p-value cutoff of $1 / 132=0.0076$, all these estrogen connections were statistically highly significant. Finally, the sediment samples, and presumably the surrounding water, near the WWTPs in Ely and Hutchinson were positive for a number of PAHs (e.g. anthracene, phenanthrene, pyrene) and an organophosphate insecticide (chlorpyrifos) [31]. The query signatures from both locations ranked

Table 5 Cmap performance under "real world" conditions

\begin{tabular}{|c|c|c|c|c|c|}
\hline Signatures (NCBI GEO accession) & 1st - 2nd match & 3rd-4th match & 5th-6th match & 7th-8th match & 9th-10th match \\
\hline \multirow[t]{2}{*}{ EFFHa_5Perc_MaleLiver_14d (GSE29350) } & self & BIF_Larvae & BIF_Larvae & Wastewater_Liver & FLU_50_Ovary \\
\hline & EFFLa_M_Liver & HutDS_Liver & EFFHb_M_Liver & HutUS_Liver & PFCs_Mix_Liver \\
\hline \multirow[t]{2}{*}{ EFFHb_5Perc_MaleLiver_14d (GSE29350) } & self & Wastewater_Liver & FAD_Ovary & TRI_Ovary & RDX_Liver \\
\hline & E2_M_Liver & HutEFF_Ovary & VIN_Ovary & KET_Ovary & RDX_fry \\
\hline \multirow[t]{2}{*}{ ElyDS_999_Liver_4d (GSE49098) } & self & HutEFF_Liver & RochUS_Liver & RochDS_Liver & PHE_Liver \\
\hline & ElyEFF_Liver & ElyUS_Liver & HutUS_Liver & HutDS_Liver & E2_M_Liver \\
\hline \multirow[t]{2}{*}{ ElyEFF_999_Liver_4d (GSE49098) } & self & ElyUS_Liver & PHE_Liver & RochDS_Liver & RochUS_Liver \\
\hline & ElyDS_Liver & HutEFF_Liver & HutUS_Liver & PHE_Liver & E2_M_Liver \\
\hline \multirow[t]{2}{*}{ ElyUS_999_Liver_4d (GSE49098) } & self & ElyDS_Liver & HutEFF_Liver & HutUS_Liver & BIF_Larvae \\
\hline & ElyEFF_Liver & PFCs_Liver & EFFHa_M_Liver & RochDS_Liver & PFCs_Mix_Liver \\
\hline \multirow[t]{2}{*}{ HutchinsonDS_999_Liver_4d (GSE49098) } & self & RochDS_Liver & HutEFF_Liver & ElyEFF_Liver & PFCs_Mix_Liver \\
\hline & RochUS_Liver & ElyDS_Liver & HutUS_Liver & KET_Ovary & KET_Ovary \\
\hline \multirow[t]{2}{*}{ HutchinsonEFF_999_Liver_4d (GSE49098) } & self & ElyDS_Liver & HutUS_Liver & HutDS_Liver & PHE_Liver \\
\hline & ElyEFF_Liver & ElyUS_Liver & RochUS_Liver & RochDS_Liver & KET_Ovary \\
\hline \multirow[t]{2}{*}{ RochesterDS_999_Liver_4d (GSE49098) } & self & HutUS_Liver & HutDS_Liver & ElyEFF_Liver & RochEFF_Liver \\
\hline & RochUS_Liver & ElyDS_Liver & ElyUS_Liver & HutEFF_Liver & BIF_Larvae \\
\hline \multirow[t]{2}{*}{ RochesterEFF_999_Liver_4d (GSE49098) } & HutUS_Liver & self & HutEFF_Liver & BIF_Larvae & PFCs_Mix_Liver \\
\hline & ElyUS_Liver & RochDS_Liver & ElyDS_Liver & RochUS_Liver & PFCs_Liver \\
\hline \multirow[t]{2}{*}{ RochesterUS_999_Liver_4d (GSE49098) } & self & RochDS_Liver & HutEFF_Liver & HutUS_Liver & ElyUS_Liver \\
\hline & ElyDS_Liver & ElyEFF_Liver & HutDS_Liver & RochEFF_Liver & PFCs_Mix_Liver \\
\hline \multirow[t]{2}{*}{ Wastewater_999_Liver_48h (GSE37550) } & self & CYP_Larvae & NA & NA & NA \\
\hline & E2_M_Liver & surfaceH2O_Testis & NA & NA & NA \\
\hline
\end{tabular}

Fathead minnow samples were exposed to various water conditions near several waste water treatment plants in the USA either by field deployment or in a laboratory setting. Only those exposures generating a significant number of DEGs thus having query signatures available are listed. The top ten matched ROGLs are listed to provide a broad list of candidate chemicals. Waste water treatment plant locations: Ely, Hutchinson (Hut), Rochester (Roch), Minnesota; San Diego $(\mathrm{Ha})$, Los Angeles (Hb), California; Gainesville (GSE37550), Florida. Abbreviations: EFF, effluent; US, upstream; DS, downstream. P-value cutoff 1/132 = 0.0076. Self: a query signature and the connected ROGLs originated from the same experiment 
phenanthrene with high connectivity scores. With the same MIE (acetylcholinesterase inhibitor) shared between terbufos and chlorpyrifos, a strong connectivity was also found between a terbufos signature and the ROGLs of Ely downstream (6th), Ely effluent (8th), Hutchinson downstream (14th), and Hutchinson effluent (16th).

Cmap had a more limited success, ranging from $50 \%$ to $85 \%$, across platforms and species based on a small number of conditions common to them (Table 2). In spite of varying performance between ZF $21 \mathrm{~K}$ and ZF $43 \mathrm{~K}$ in either direction, Cmap was able to connect query signatures to target ROGLs for all the conditions common to these two platforms: EE2/E2/genistein, flutamide, and prochloraz (Table 6, Additional file 4: Table S3). There was little difference in cross-platform performance between maximum signature size set at 100 and 500. Similar variation in the performance of Cmap was also observed across species. Among the conditions shared between FHM $15 \mathrm{~K}$ and ZF $21 \mathrm{~K}$, and between FHM $15 \mathrm{~K}$ and ZF 43K, were EE2/E2/DES/genistein, trenbolone, and RDX. With the exception of RDX and trenbolone, successful connections were made between query signatures and ROGLs for all other conditions.

\section{Discovery of novel chemical connections}

While the chemical identities of individual query signatures and their connected high-scored ROGLs enable an evaluation of Cmap performance, those connections that ranked high across query signatures also could provide novel insights into possibly shared MOAs and toxicity pathways among seemingly different chemicals. By individual platforms of ZF $21 \mathrm{~K}$, ZF $43 \mathrm{~K}$, and FHM $15 \mathrm{~K}$, the

Table 6 Top five significant hits, if any, of selected Cmap queries across microarray platforms and species

\begin{tabular}{|c|c|c|c|c|c|}
\hline Signatures & 1st match & 2nd match & 3rd match & 4th match & 5th match \\
\hline & \multicolumn{5}{|c|}{ From ZF $21 \mathrm{~K}$ to ZF 43K ( $\mathrm{p}$-value $=0.026$; signature size average $=181, \min =15, \max =375$ ) } \\
\hline EE2_30ngL_M_Brain_48hr.sig.500.IDswap & LIN_Embryo & PRO_F_Brain & LIN_Embryo & E2_M_Liver & FLU_Ovary \\
\hline EE2_30ngL_M_Liver_48hr.sig.500.IDswap & E2_M_Liver & RDX_fry & RDX_fry & RDX_fry & PKC412_fish \\
\hline EE2_30ngL_M_Testis_48hr.sig.500.IDswap & GEN_Embryo & BPA_Ovary & BPA_Embryo & BPA_Ovary & DBT_Embryo \\
\hline FLU_Ovary_48hr.sig.500.IDswap & FLU_Embryo & PKC412_fish & BPA_Ovary & PPL_Embryo & RDX_fry \\
\hline FLU_Testis_48hr.sig.500.IDswap & LIN_Embryo & LIN_Embryo & FLU_F_Ovary & PKC412_fish & FLU_Embryo \\
\hline PRO_F_Brain_48hr.sig.500.IDswap & E2_M_Liver & PRO_F_Brain & GEN_Embryo & FLU_Embryo & PRO_Ovary \\
\hline PRO_Ovary_48hr.sig.500.IDswap & PRO_Ovary & FLU_Ovary & PRO_F_Brain & & \\
\hline \multirow[t]{2}{*}{ PRO_Testis_48hr.sig.500.IDswap } & E2_M_Liver & PRO_Ovary* & PRO_F_Brain* & & \\
\hline & \multicolumn{5}{|c|}{ From ZF $43 \mathrm{~K}$ to $Z F 21 \mathrm{~K}(\mathrm{p}$-value $=0.022 ;$ signature size average $=134, \min =5, \max =310$ ) } \\
\hline E2_1uM_Embryo_4dpf.sig.500.IDswap & EE2_Testis & EE2_M_Liver & TRB_F_Liver & O2_Testis & O2_Ovary \\
\hline E2_5ugL_M_Liver_4hrs.sig.500.IDswap & EE2_M_Liver & TRB_F_Liver & O2_Testis & O2_Testis & TCDD_Embryo \\
\hline \multirow[t]{2}{*}{ PRO_2mgL_Embryo_48hr.sig.500.IDswap } & DMB_Embryo & tBHQ_Embryo & TRB_F_Brain & PRO_F_Brain & EE2_M_Liver \\
\hline & \multicolumn{5}{|c|}{ From ZF $21 \mathrm{~K}$ to FHM $15 \mathrm{~K}(\mathrm{p}$-value $=0.0076$; signature size average $=124, \min =9, \max =257$ ) } \\
\hline EE2_30ngL_Ovary_96hr.sig.500.IDswap & FAD_Ovary & EE2_M_Brain & EE2_M_Brain* & & \\
\hline EE2_30ngL_M_Liver_48hr.sig.500.IDswap & EE2_Liver & RochDS_liver & PHE_Liver & RochUS_liver & Stream_Liver \\
\hline \multirow[t]{2}{*}{ EE2_30ngL_Testis_48hr.sig.500.IDswap } & PFCs_Liver & KTC_Ovary & PFCs_High_Liver & RochEFF_liver & \\
\hline & \multicolumn{5}{|c|}{ From FHM $15 \mathrm{~K}$ to ZF $21 \mathrm{~K}(\mathrm{p}$ - value $=0.022 ;$ signature size average $=110, \min =5, \max =272$ ) } \\
\hline DES_100ngL_Liver_96h.sig.500.IDswap & EE2_M_Liver & DNP_Embryo & DMB_Embryo & TCDD_Embryo & APM_Embryo \\
\hline E2a_4ugL_M_Liver_14d.sig.500.IDswap & EE2_M_Liver & KET_F_Liver & DNP_Embryo & KET_M_Liver & TRI_Ovary \\
\hline \multirow[t]{2}{*}{ EE2_25ngL_Liver_72h.sig.500.IDswap } & EE2_M_Liver & KET_M_Liver & KET_F_Liver & TRB_F_Liver & FLU_M_Testis \\
\hline & \multicolumn{5}{|c|}{ From ZF 43K to FHM 15K ( $p$-value $=0.0076$; signature size average $=120, \min =6, \max =274$ ) } \\
\hline E2_M_Liver_4hrs.sig.500.IDswap & ElyEFF_liver & ElyDS_liver & PHE_Liver & E2_M_Liver & DES_Liver \\
\hline \multirow[t]{2}{*}{ GEN_Embryo_48hr.sig.500.IDswap } & PFCs_Blood & KTC_Ovary & BIF_Larvae & E2_M_Liver & PER_Larvae \\
\hline & \multicolumn{5}{|c|}{ From FHM $15 \mathrm{~K}$ to $Z$ F $43 \mathrm{~K}$ ( $\mathrm{p}$-value $=0.026$; signature size average $=139, \min =5, \max =363$ ) } \\
\hline DES_1ngL_Liver_96h.sig.500.IDswap & E2_M_Liver & & & & \\
\hline E2_4ugL_M_Liver_14d.sig.500.IDswap & E2_M_Liver & PKC412_fish & BPA_Embryo & GEN_Embryo & BPA_Embryo \\
\hline EE2_25ngL_Liver_72h.sig.500.IDswap & E2_M_Liver & PKC412_fish & LIN_Embryo & BPA_Embryo & BDE_Embryo \\
\hline
\end{tabular}

Where similar signatures exist for a condition, only one of them is listed. ROGL hits are ranked by their adjusted connectivity scores and filtered by a p-value cutoff of $1 /$ (number of sets of ROGLs). Informative connections, defined as a signature and one of its top five ROGL hits sharing the same or similar class of chemicals, are highlighted in bold. "**", $p$-values slightly greater than the cutoffs 
highest-scored connection was selected from all the significant ones for each distinct pair of chemicals, regardless of direction (i.e., two conditions linked to each other as either a signature or ROGLs), tissue type, dose, exposure duration or data origin, and visualized collectively in Cytoscape as a chemical network. With the recognition of likely confounding contributions from such factors as tissue type, this network provided a composite or "average" view of how chemicals relate to one another. Each chemical in this network became a node, with the connection between two nodes forming an edge. An edge was weighted by the connectivity score between the two connected chemicals. Such a network essentially provides a glimpse of chemical "neighborhood" as arranged by the similarities in the transcriptomic profiles among its chemical members.

In ZF $21 \mathrm{~K}$ where a total of 17 chemicals were linked, 10 confirmed HPG-active toxicants formed a tight cluster in the network while other chemicals that likely were not HPG-active spread out as distant outliers (Fig. 1a). A further differentiation of the 10 HPG-active toxicants could be made when they were selected to form their own sub-network based on achieving a minimum connectivity score (Fig. 1b). Under this scenario, there appeared to be two distinct groups: one made up of vinclozolin, ketoconazole, flutamide, trilostane, fipronil, muscimol, and prochloraz; and the other of EE2 and fadrozole. Trenbolone seemed to be unique as it shared substantial similarity to both groups. These observed clustering patterns were still clearly visible when both chemical and tissue type were considered together (Additional file 5: Figure S2). Beyond the contributions from chemical and sometimes tissue type, the structure of this network did not appear to coincide with other experimental conditions such as the lab origins of data.

In ZF $43 \mathrm{~K}$, there was also a distinct pattern in chemical connectivity (Fig. 1c, d). Prochloraz, flutamide, linuron, E2, and to the lesser extent, EE2, methylparaben, bisphenol A, formed a group of similar chemicals while RDX, PKC412, and diazepam formed another. Interestingly, the three confirmed estrogens; genistein, EE2, and E2; had relatively weak connections among themselves.

In FHM 15K, a number of interesting observations could also be made. Consistent with the earlier analysis

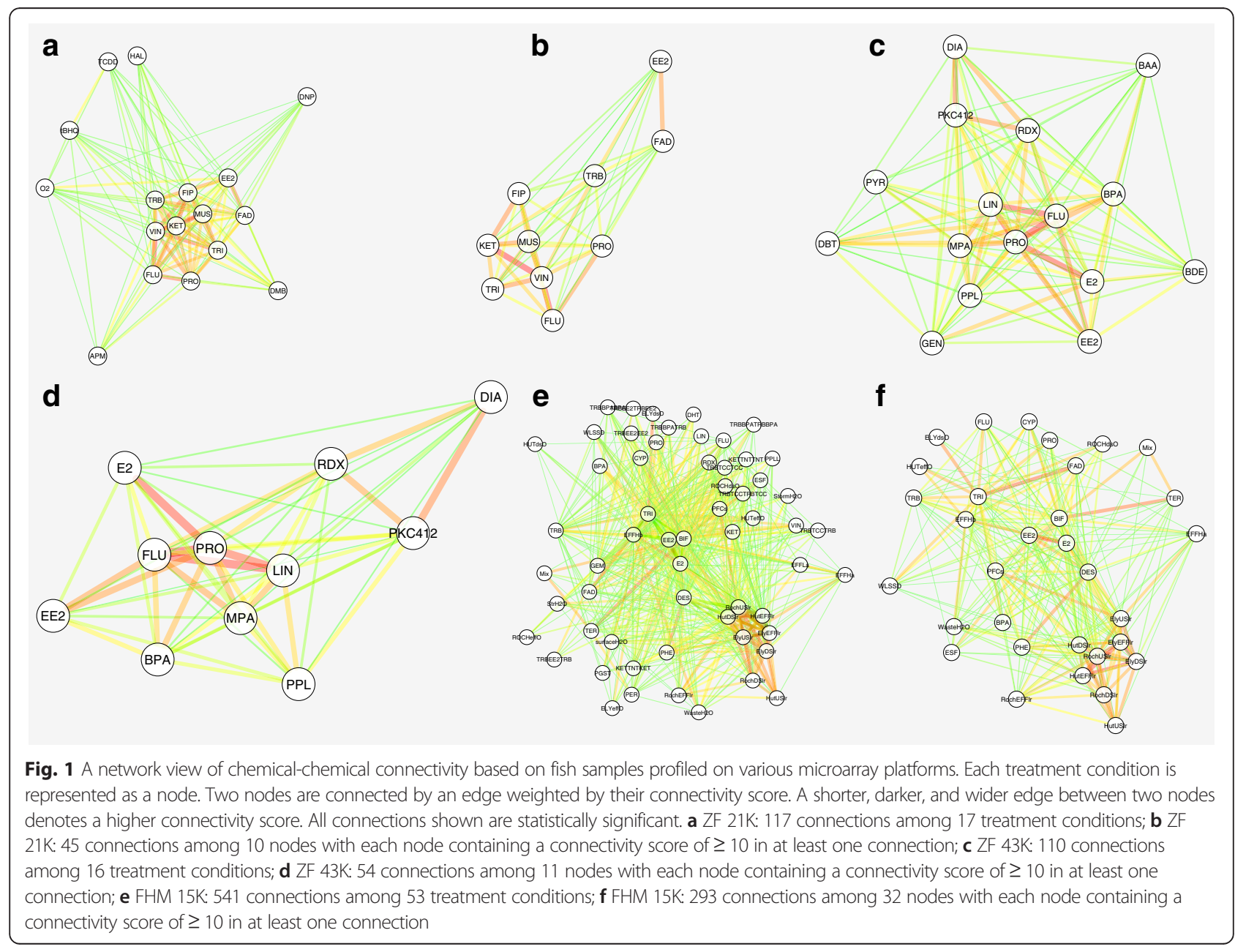


by individual query signatures (Table 5), the water conditions near the three Minnesota WWTPs, as reflected in the transcriptomic profiles of deployed male fish, were indeed highly similar to one another not only across sites within a location, but also across locations (Fig. 1e, f; liver tissue of male fish exposed to water from Ely effluent, downstream, upstream: ElyEFFlr, ElyDSlr, ElyUSlr; Hutchinson effluent, downstream, upstream: HutEFFlr, HutDSlr, HutUSlr; Rochester effluent, downstream, upstream: RochEFFlr, RochDSlr, RochUSlr). These sites, all of which had detectable estrogens present [30], showed relatively strong connectivity with diethylstilbestrol (DES), E2, and EE2. However, in female fish samples exposed to these same sites (ELYeffO, ELYdsO, HUTdsO, HUTeffO, ROCHeffO, ROCHdsO), no detectable impact was found on gene expression, and perhaps not surprisingly, no obvious pattern in the connectivity among these conditions was observed. In a similar but independent study of WWTPs in San Diego (EFFHa, EFFLa) and Los Angeles (EFFHb), California [29], potential estrogenic properties as determined by chemistry were revealed in the current study by their significant connectivity to DES, E2, and EE2. Also notable is the fact that, probably due to the San Diego WWTP being a primary treatment plant and the Los Angeles WWTP a secondary treatment plant, their ROGLs were quite distinct. Finally, several pyrethroid insecticides (bifenthrin, BIF; cypermethrin, CYP; esfenvalerate, ESF), though seemingly far apart, also shared strong connectivity among themselves as indicated by their edge size and color. In the case of a mixture (Mix) of terbufos (TER) and permethrin (PER), the mixture was strongly connected to both terbufos and bifenthrin, but not to permethrin directly. Interestingly, permethrin was significantly linked to both terbufos and bifenthrin (Fig. 1e, Table 4).

Connectivity among chemicals appeared to be modulated by the intensity of their elicited transcriptomic responses, which are dependent on chemical dose, treatment duration, fish tissue type, and life stage. When only fathead minnow treatments with multiple doses of the same tissue type were considered, the nodes of the same chemical but with various doses were scattered throughout the network, with different numbers of neighbors (directly connected nodes) at different connectivity strength (Fig. 2). For a given node, the number of its neighbors measures its connectivity in a network. For instance, the two nodes representing two independent but concurrent bifenthrin exposure experiments with larvae (BIF_0.148ugL, BIF_0.593ugL) had 7 and 4 neighbors respectively, as determined by Cytoscape. Their closest neighbors by connectivity score, bifenthrin (BIF_0.15ugL, 7.2) and trilostane (TRI_1500ugL, 4.8) respectively, were also different. In other words, depending on dosage, the network neighborhood of a chemical could be altered to some extent. Similar observations were also made in other conditions such as bisphenol A with ovary (BPA_0.01ugL, BPA_0.1ugL, BPA_1.0ugL, BPA_10ugL, and BPA_100ugL; 9, 4, 7, 9, 11 neighbors), DES with liver (DES_1ngL, DES_10ngL, DES_100ngL; 10,8 , and 47 neighbors), and fadrozole with ovary (FAD_3ugL, FAD_5ugL, FAD_30ugL, FAD_50ugL; 8, 10, 8,11 neighbors).

\section{Discussion}

Fish Cmap provides a data-driven approach for applying transcriptome profiling technology to the assessment of exposure, relative toxicity, and grouping of chemicals. The findings in this study have demonstrated the effectiveness of this approach to make connections among chemical conditions associated with a query signature and a set of ROGLs from independent experiments, especially when both are from the same microarray platform/species. Like any other query-database applications, its power is a function of coverage: the more chemical/biological conditions ROGLs in a database are linked to, the more likely a query signature will make an informative connection. Along with the rapid increase of transcriptomics data in public repositories and the expansion of this fish reference database in the future, fish Cmap should find increasing applications in ecotoxicology.

The performance of fish Cmap ultimately depends on MOAs/toxicity pathways shared among chemicals. For a given query signature and its target ROGLs, the connectivity strength is determined by both the direction in change (up, + or down, -) and ranking in magnitude of the selected DEGs therein (typically 10 to 100). In the current study, the direction of DEGs was considered in both signatures and ROGLs, but the ranking was considered only in ROGLs. In this configuration, a connectivity score is maximized when the signs of DEGs in a query signature perfectly match their counterparts in the target ROGLs, and these DEGs are ranked high in the latter [24]. Arguably, the direction of change of a DEG and its relative rank are not as sensitive as magnitude to extraneous factors such as exposure intensity (chemical dosage and duration) and "random" noise (natural variation; Wang et al. [16]), thus are more reflective of the underlying chemical MOA. In theory, a treatment condition must be of sufficient intensity to have a significant impact on fish transcriptome and enable subsequent Cmap. The relationship between connectivity strength and the magnitude of treatment effect as indicated by DEGs was examined in the current study by several measures of individual chemical conditions: relative transcriptome impact (RTI, the percentage of a transcriptome determined as DEGs), the average LogFC in absolute values over all 


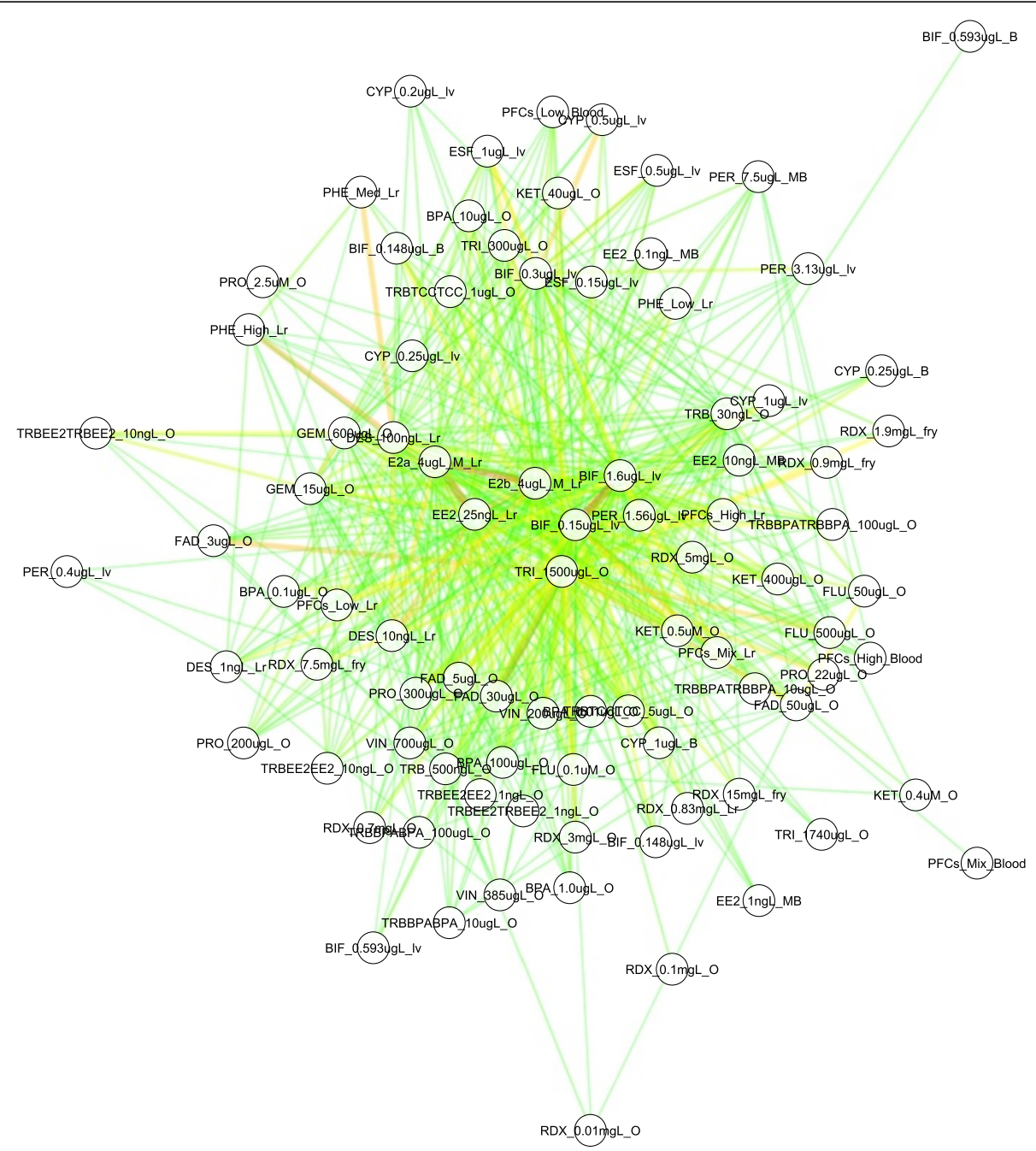

Fig. 2 A network view of chemical-chemical connectivity based on fish samples profiled on FHM 15K. Only treatments with multiple doses are included. Each treatment condition containing the information of both dosage and tissue type is represented as a node. Two nodes are connected by an edge weighted by their connectivity score. A shorter, darker, and wider edge between two nodes denote a higher connectivity score. All connections shown are statistically significant. Tissue types and gender: T, testis; O, ovary; B, brain; Lr, liver; Iv, larvae; M, male

DEGs, and total number of DEGs. There were no clear relationships for connectivity score (normalized to signature size), RTI, and average LogFC (Additional file 6: Figure S3A, S3B, S3C) among 106 chemical conditions with a $\mathrm{RTI} \geq 0.001$. However, a further examination within FHM 15K, which has 13 signatures each containing less than 10 probes, revealed that connectivity scores (un-normalized) tended to increase as a function of total number of DEGs (Additional file 7: Table S4). All 11 unsuccessful queries (measured by p-value of 0.0076 in top five hits) occurred in conditions in which each had less than 100 DEGs in total. On the other hand, many chemical conditions with very few detectable DEGs were actually still able to yield informative ROGLs to allow appropriate connections with relevant query signatures. These pieces of evidence thus reinforce the importance of DEGs' directions of change and rankings to chemical connectivity in comparison to their LogFC, and the importance of guarding against false positives when a treatment condition has only minimal effects. Furthermore, Cmap connectivity should, in theory, be largely driven by chemical MOAs because both signatures and ROGLs were generated within the same tissue type between a treatment condition and corresponding experimental controls. Indeed, Cmap performed very well in connecting query signatures to their target ROGLs, especially within platforms/species. These connections were often made across experimental origins, chemical classes, complexity of exposures, and tissue types. As illustrated by fish samples from ZF $21 \mathrm{~K}$, when the connections of associated chemicals and tissue types were visualized simultaneously in a network, many nodes were 
distributed based on chemical conditions, not tissue types (Additional file 5: Figure S2A, S2B). However, it is evident that, in some cases, tissue type did contribute significantly to chemical connectivity. Such a confounding effect is probably a function of chemical, dosage, and tissue type.

Besides making a greater amount of public fish transcriptomic data available for Cmap, the primary significance in attempting interspecific Cmap lies in the prospect of extrapolating chemical toxicity across fish species. This is critical because it is impossible to test the toxicity of all chemicals of possible concern in all fish species. There are two potential limiting factors affecting the success of interspecific (inter-platform) Cmap. One is genome annotation and probe mapping to identify orthologous/equivalent probes. The other is the conservation of toxicity pathways/ MOAs between species. Given a very small number of conditions common across platforms and species in this study, it is difficult to assess Cmap performance across platforms/ species reliably. However, generally low percentages of cross-mapped probes $(62 \%$ of ZF $21 \mathrm{~K}$ vs $37 \%$ of ZF 43K; $43 \%$ of ZF $21 \mathrm{~K}$ vs $45 \%$ of FHM $15 \mathrm{~K} ; 38 \%$ of ZF $43 \mathrm{~K}$ vs $65 \%$ of FHM 15K) suggest that a substantial loss of information was probably responsible in part for the relatively poor performance in the preliminary Cmap across platforms/species. With the relatively recent divergence between zebrafish and fathead minnow [15], broad conservation of molecular pathways among animal species [32-38], and high degree of genome conservation even between zebrafish and human [39], it seems reasonable to hypothesize that toxicity pathways are well conserved between these two small fish species. Indeed, a recent study of their transcriptomes provided strong evidence in this regard [16]. If this is the case, conservation of toxicity pathways should not be the primary issue in the performance of interspecific Cmap in the current study.

In addition to being able to connect the same chemicals underlying a query signature and its target ROGLs, Cmap also provided novel insights into some seemingly different chemicals that may possess similar MOAs. For those studies based on ZF $21 \mathrm{~K}$, Cmap grouped several wellcharacterized HPG-active toxicants together (Fig. 1a) [18], and further differentiated them into two sub-groups (Fig. 1b). One subgroup consisted of EE2 and fadrozole only; the other included vinclozolin, ketoconazole, flutamide, trilostane, fipronil, muscimol, and prochloraz. Trenbolone appeared to be an intermediate between the two subgroups. These clustering patterns did not correlate with extraneous factors such as tissue type or lab origins of data. For example, four different research groups produced data behind these nodes: oxygen, haloperidol and 10 other HPG-active toxicants; tetrachlorodibenzo-pdioxin (TCDD); TCDD, tert-butylhydroquinone; dinitrophenol, dimethoxybenzene, and azinphosmethyl. Rather, the distribution patterns of these chemicals are more in line with their MOAs, some of which involve multiple MIEs. As an aromatase inhibitor, fadrozole blocks the transformation of testosterone to E2, the primary endogenous ligand for the estrogen receptor (ER), so it is reasonable that EE2 and fadrozole would cluster together. Further, since testosterone is a ligand for the androgen receptor (AR), it is quite conceivable to envision the same genes being activated by EE2, fadrozole, and trenbolone, a synthetic AR agonist [40,41]. A similar argument could also be invoked to explain the shared MOAs of vinclozolin, flutamide, ketozonazole, and to a lesser extent, prochloraz, because of their common impact again on AR and aromatase: vinclozolin, flutamide, prochloraz are all AR antagonists, while ketoconazole and prochloraz are both aromatase inhibitors [18]. Note that fadrozole also shared strong connectivity with ketoconazole and prochloraz. There are other examples, as well, of the Cmap analysis highlighting chemicals that impact the same molecular target. For example, although fipronil and muscimol have opposite effects on gamma-aminobutyric acid (GABA) receptor, one being an antagonist while the other an agonist, they are identified as substantially similar. Between muscimol (MUS_500ugL_femaleBrain) as a signature and fipronil (FIP_5ugL_femaleOvary) as ROGLs, they reached a high connectivity score of 16.8 (ranged 2.5-23.6 in ZF 21K), with the corresponding average LogFC of only 0.42 and 0.33 . In other words, these DEGs changed largely in the same direction and ranked high in both muscimol and fipronil-treated fish, despite the differences in tissue being examined.

Novel insights on chemical MOAs were gained as well from studies based on ZF 43K and FHM 15K. For ZF 43K-based studies, chemicals acting as AR antagonists, prochloraz and flutamide, had MOAs similar to those of ER agonists, E2 and EE2 (Fig. 1c, d), suggesting that, at some level, anti-androgens and ER agonists are somewhat functionally equivalent biologically. Indeed, bisphenol A, a compound known to exhibit both estrogenic and anti-androgenic effects [42, 43], showed substantial connectivity with prochloraz (score 12.0), flutamide (10.8), EE2 (8.9), and E2 (6.8). The strength of these connections represents 37-65\% of the maximum connectivity score observed in the ZF 43K-based studies. Linuron, a phenylurea herbicide and a confirmed anti-androgen [44], also formed strong connections to prochloraz and flutamide. Methylparaben, a common preservative in cosmetic products, has been shown to possess both estrogenic and anti-androgenic activities [45].

For FHM 15K-based studies (Fig. 1e, f), Cmap demonstrated its effectiveness in discriminating chemical exposures across a range of complexities. For single chemical exposures, strong connectivity was found among several MOA-based classes of chemicals including ER agonists 
(EE2, E2, DES), neuro-toxins (bifenthrin, permethrin, cypermethrin, esfenvalerate, terbufos), and inhibitors of steroidgenic enzymes $3 \beta$-HSD and aromatase (trilostane, fadrozole). Phenanthrene, a PAH, was also linked to DES, suggesting its possible estrogenicity.

Also notable is the fact that when a chemical condition has little detectable transcriptomic effect perhaps due to issues such as effective dosage, sample size, and statistical stringency, its ROGLs still could be informative and capable of connecting with appropriate query signatures. This was the case in a mixture of permethrin and terbufos, where, in the absence of its own signature and a sizeable signature from permethrin alone, its ROGLs could still connect with bifenthrin and terbufos. And so did the ROGLs from permethrin. Other than both being neurotoxins but with different MIEs, bifenthrin and terbufos are not known to share any other mechanisms underlying their connectivity. Perhaps a more striking revelation came from male fathead minnow liver samples exposed to the effluents near several WWTPs in Minnesota, which contained a complex array of chemicals including several known estrogens, PAHs, and a neuro-toxin [30, 31]. In spite of being located in very different ecological environment (non-agricultural, agricultural, urban), the effluents of these plants were remarkably similar to one another as measured by their common impact on fish transcriptomes. Quite possibly, the main drivers behind such a similarity include PAHs, natural and synthetic ER agonists, as well as other pollutants, rather than agricultural chemicals. There was, in fact, substantial connectivity between the effluent samples and several single chemical studies with known PAHs (maximum score 10.5) and estrogens (maximum score of 9.4) as compared to the observed score range of 2.6 to 19.9 for FHM 15K (Fig. 1e, f). These same effluents, however, had hardly any effect on the ovaries of female fish samples treated in the same study; some of their representative nodes present in the network were widely scattered. Thus, across the research based on the three platforms, ZF $21 \mathrm{~K}$, ZF 43K, and FHM 15K, Cmap has demonstrated its effectiveness in not only connecting the same chemical conditions underlying query signatures and ROGLs, but also establishing novel connectivity among seemingly different chemicals based on shared MOAs.

Connectivity among chemicals is a function of their shared transcriptomic profiles, which in turn are likely modulated by the dose and duration of a treatment on the targeted fish tissue at a given life stage. Conceivably, a varying number of genes and pathways could become perturbed by the same chemical under different conditions, leading to a different degree of overlap among MOAs. This hypothesis is supported by the findings in the current study, where the same chemical tested at multiple doses had different number of neighbors in a network of chemicals. Similar observations of dose-dependent, differential transcriptomic responses were also reported recently for chemicals in human cell cultures and fish $[46,47]$. Such a dependency between chemical dose and transcriptomic response have both scientific and practical implications for applying Cmap in ecotoxicology. Scientifically, a chemical MOA could then be considered as consisting of both core and peripheral toxicity pathways, which may be defined by their responsiveness as a function of exposure intensity (dosage and duration), the specificity to a given chemical or tissue type, or the importance to the integrity of their larger biological network. The earliest responders at the lowest exposure intensity may not be necessarily those most critical to an organism's biological integrity. A better delineation of toxicity pathways in this regard should help to inform the assessment of relative toxicity among chemicals and their risks to ecosystems. For more practical application of Cmap in exposure assessment, however, those chemical-specific, earliest responsive pathways at the lowest exposure intensity are likely to be diagnostically useful in biomonitoring.

\section{Conclusions}

In summary, fish Cmap built on a very large collection of public and private GEPs from zebrafish and fathead minnow performed well in this study, particularly when conducted within the same platforms/species. When a query signature from samples of interest was made against a reference database of ROGLs, informative connections were established at high success rates when both shared the same chemical conditions. In other words, Cmap provides an easily scalable framework for a simple query signature selected from DEGs to function as an exposure biomarker, without going through a typical time-consuming process of development and validation. More importantly, as demonstrated in this study, a large reference database of ROGLs also enables a query signature to cross interrogate other chemical conditions with overlapping MOAs, leading to novel groupings and subgroupings of seemingly unrelated chemicals at a finer resolution. By this approach, for example, the estrogenic and PAH identities of largely uncharacterized water samples near several WWTPs were confirmed, suggesting its future potential in real world applications. For toxicity extrapolation across fish species, however, a sufficient number of GEPs linked to chemical conditions common to multiple fish species are needed in the future in order to conduct a more thorough feasibility study of interspecific Cmap.

\section{Availability of supporting data}

The data sets supporting the results of this article are available in the NCBI GEO repository, with the accession numbers GSE38070, GSE60202, GSE70807, and GSE70936. Additional datasets downloaded from GEO are listed in Additional file 1: Table S1. 


\section{Additional files}

Additional file 1: Table S1. A complete list of microarray data used in the current study. (XLSX $111 \mathrm{~kb}$ )

Additional file 2: Table S2. A complete list of query signatures constructed in the current study. Signatures were named after fish sample treatment conditions by the order of chemical, dose, gender, tissue, and exposure duration. Some conditions may each have multiple signatures generated because of either repeated experiments or different parameters in analysis. (XLSX $19 \mathrm{~kb}$ )

Additional file 3: Figure S1. Relative transcriptomic impact of various treatment conditions in fathead minnow. Effects are measured by the percentages of transcriptome determined to be DEGs. (PPTX $39 \mathrm{~kb}$ )

Additional file 4: Table S3. Cmap across ZF $21 \mathrm{~K}$ and ZF $43 \mathrm{~K}$ with the maximum signature size of 100 probes. (DOCX $14 \mathrm{~kb}$ )

Additional file 5: Figure S2. A network view of chemicals and tissue types based on samples profiled on ZF 21K. Each chemical treatment condition and the tissue profiled is represented as a node. Two nodes are connected by an edge weighted by their connectivity score. A shorter, darker, and wider edge between two nodes denote a higher connectivity score. All connections shown are statistically significant. A) 40 nodes with 573 connections; B) 30 nodes with 380 connections with each node having a minimum connectivity score of 10 in at least one of its connections. Tissue types: T, testis; O, ovary; B, brain; Lr, liver. (PDF $37 \mathrm{~kb}$ )

Additional file 6: Figure S3. Relationships between connectivity strength and DEGs. A total of 106 chemical conditions with relative transcriptomic impact $\geq 0.001$ were considered. Connectivity scores were normalized to the size of respective query signatures. A) average LogFC vs connectivity scores; B) average logFC vs relative transcriptomic impact (RTI, percentage of transcriptome as DEGs); C) connectivity scores vs RTIs. (PPTX $49 \mathrm{~kb}$ )

Additional file 7: Table S4. Relationship between total number of DEGs and connectivity score among treatment conditions within FHM 15K. (XLSX 24 kb)

\section{Abbreviations}

Agilent 013223: ZF 21K; Agilent 015064: ZF 21K; Agilent 019161: ZF 43K Agilent 019597 036574: FHM 15K; APM: azinphos-methyl;

BAA: benz(a)anthracene; BDE: decabromodiphenyl ether; BIF: bifenthrin; BPA: bisphenol A; CYP: cypermethrin; DBT: dibenzothiophene; DES: Diethylstilbestrol; DHT: Dihydrotestosterone; DIA: Diazepam; DMB: 1,4dimethoxybenzene; DNP: 2,4-dinitrophenol; E2: 17ß-estradiol; EE2: ethniyl estradiol; EFFHa: Effluent of WWTP in San Diego, California; EFFHb: Effluent of WWTP in Los Angeles, California; EFFLa: Effluent of WWTP in San Diego, California; ELYds: Downstream of WWTP in Ely, Minnesota (ovary tissue sampled); ElyDS: Downstream of WWTP in Ely, Minnesota (liver tissue sampled); ELYeff: Effluent of WWTP in Ely, Minnesota (ovary tissue sampled); ElyEFF: Effluent of WWTP in Ely, Minnesota (liver tissue sampled);

ElyUS: Upstream of WWTP in Ely, Minnesota (liver tissue sampled) ESF: esfenvalerate; FAD: fadrozol; FIP: fipronil; FLU: flutamide; GEM: Gemfibrozil; GEN: genistein; HAL: Haloperidol; HUTds: Downstream of WWTP in Hutchinson, Minnesota (ovary tissue sampled); HutDS: Downstream of WWTP in Hutchinson, Minnesota (liver tissue sampled); HUTeff: Effluent of WWTP in Hutchinson, Minnesota (ovary tissue sampled); HutEFF: Effluent of WWTP in Hutchinson, Minnesota (liver tissue sampled): HutUS: Upstream of WWTP in Hutchinson, Minnesota (liver tissue sampled); KET: ketochonazole; LIN: Linuron; LSW: Lake Superior water; MPA: methylparaben; MUS: muscimol; O2: oxygen; PER: permethrin; PFC: perflorinated chemicals; PGST: Progesterone; PHE: Phenanthrene; PKC412: protein kinase C inhibitor 412; PPL: Propanil; PPLL: Propranolol; PRO: prochloraz; PYR: Pyrene; RDX: cyclotrimethylenetrinitramine; ROCHds: Downstream of WWTP in Rochester, Minnesota (ovary tissue sampled); RochDS: Downstream of WWTP in Rochester, Minnesota (liver tissue sampled); ROCHeff: Effluent of WWTP in Rochester, Minnesota (ovary tissue sampled); RochEFF: Effluent of WWTP in Rochester, Minnesota (liver tissue sampled); RochUS: Upstream of WWTP in Rochester, Minnesota (liver tissue sampled); stormH2O: storm water: strH2O: stream water; TBHQ: tert-Butylhydroquinone; TCC: Triclocarban;
TCDD: 2,3,7,8-tetrachlorodibenzo-p-dioxin; TER: Terbufos; TNT: 2,4,6trinitrotoluene; TRB: trenbolone; TRI: trilostane; VIN: vinclozolin; wasteH2O: waste water; WLSSD: Effluent, Western Lake Superior Sanitary District, Duluth, Minnesota; WWTP: waste water treatment plant.

\section{Competing interests}

The authors declare that there are no competing interests.

\section{Authors' contributions}

RLW, ADB, and DCB conceptualized and proposed this study. DLV, GTA, DCB, $A D B, N G-R$, and EJP conducted fish exposures to various chemicals. NG-R, EJP, DCB, and ADB contributed microarray work. RLW conducted all the bioinformatic analyses and prepared the manuscript. All coauthors contributed to the manuscript revisions and approved the final version for submission.

\section{Acknowledgements}

Funding for zebrafish exposures and microarray analysis was provided by US Environmental Protection Agency (USEPA). The U.S. Army

Environmental Quality and Installations program and U.S. Army (grant BAA 11-4838) provided funding for fathead minnow microarrays analysis. The funders had no role in study design, data collection and analysis, or preparation of the manuscript. We thank Lynn Escalon and Xin Guan in the Environmental Laboratory, US Army Engineer Research and Development Center for microarray data generation. The internal technical review was conducted by Mark Nelms at the National Health and Environmental Effects Research Laboratory, USEPA. The views expressed in this article are those of the authors and do not necessarily represent the views or policies of the USEPA. The manuscript has been approved for publication by USEPA and US Army Corps Chief of Engineers.

\section{Author details}

${ }^{1}$ Exposure Methods \& Measurements Division, National Exposure Research Laboratory, US Environmental Protection Agency, 26 W Martin Luther King Dr., MS 587, Cincinnati, OH 45268, USA. ²Environmental Laboratory, US Army Engineer Research and Development Center, US Army Corps of Engineers, 3909 Halls Ferry Rd, Vicksburg, MS 39180, USA. ${ }^{3}$ Mid-Continent Ecology Division, National Health and Environmental Effects Research Laboratory, US Environmental Protection Agency, 6201 Congdon Boulevard, Duluth, MN 55804, USA.

Received: 27 July 2015 Accepted: 19 January 2016 Published online: 28 January 2016

\section{References}

1. US EPA. 2015. TSCA chemical substance inventory. http://www.epa.gov/tscainventory. Accessed July 72015.

2. National Research Council. Scientific Frontiers in Developmental Toxicology and Risk Assessment. Washington: The National Academies Press; 2000.

3. National Research Council. Toxicity Testing in the 21st Century: A Vision and a Strategy. Washington: The National Academies Press; 2007.

4. National Research Council. Science and Decisions: Advancing Risk Assessment. Washington: The National Academies Press; 2009.

5. National Research Council. Exposure Science in the 21st Century: A Vision and a Strategy. Washington: The National Academies Press; 2012.

6. Lamb J, Crawford ED, Peck D, Modell JW, Blat IC, Wrobel MJ, et al. The Connectivity Map: Using Gene-Expression Signatures to Connect Small Molecules, Genes, and Disease. Science. 2006;313:1929-35.

7. Qu X, Rajpal DK. Applications of Connectivity Map in drug discovery and development. Drug Discov Today. 2012;17:1289-98.

8. Lincscloud. http://www.lincscloud.org/. Accessed July 8, 2015.

9. Kupershmidt I, Su QJ, Grewal A, Sundaresh S, Halperin I, Flynn J, et al. Ontology-based meta-analysis of global collections of high-throughput public data. PLoS One. 2010. doi:10.1371/journal.pone.0013066.

10. Smalley JL, Gant TW, Zhang SD. Application of connectivity mapping in predictive toxicology based on gene-expression similarity. Toxicology. 2010; 268:143-6.

11. Caiment F, Tsamou M, Jennen D, Kleinjans J. Assessing compound carcinogenicity in vitro using connectivity mapping. Carcinogenesis. 2014; 35:201-7. 
12. Wang K, Weng Z, Sun L, Sun J, Zhou S-F, He L. Systematic drug safety evaluation based on public genomic expression (Connectivity Map) data: Myocardial and infectious adverse reactions as application cases. Biochem Biophys Res Commun. 2015;457:249-55.

13. Grunwald DJ, Eisen JS. Headwaters of the zebrafish - emergence of a new model vertebrate. Nat Rev Genet. 2002;3:717-24.

14. Ankley GT, Villeneuve DL. The fathead minnow in aquatic toxicology: past, present and future. Aquat Toxicol. 2006;78:91-102.

15. Wang XZ, Li JB, He SP. Molecular evidence for the monophyly of East Asian groups of Cyprinidae (Teleostei: Cypriniformes) derived from the nuclear recombination activating gene 2 sequences. Mol Phylogenet Evol. 2007;42: 157-70.

16. Wang R-L, Bencic DC, Garcia-Reyero N, Perkins EJ, Villeneuve DL, Ankley GT, et al. Natural Variation in Fish Transcriptomes: Comparative Analysis of the Fathead Minnow (Pimephales promelas) and Zebrafish (Danio rerio). PLoS One. 2014. doi:10.1371/journal.pone.0114178.

17. Ankley GT, Bennett RS, Erickson RJ, Hoff DJ, Hornung MW, Johnson RD, et al. Adverse outcome pathways: a conceptual framework to support ecotoxicology research and risk assessment. Environ Toxicol Chem. 2010;29:730-41.

18. Ankley GT, Bencic DC, Breen MS, Collette TW, Conolly RB, Denslow ND, et al. Endocrine disrupting chemicals in fish: developing exposure indicators and predictive models of effects based on mechanism of action. Aquat Toxicol. 2009;92:168-78

19. Skolness SY, Durhan EJ, Garcia-Reyero N, Jensen KM, Kahl MD, Makynen EA, et al. Effects of a short-term exposure to the fungicide prochloraz on endocrine function and gene expression in female fathead minnows (Pimephales promelas). Aquat Toxicol. 2011;103:170-8.

20. Villeneuve DL, Garcia-Reyero N, Lynn E, Jensen KM, Cavallin JE, Makynen EA, et al. Ecotoxicogenomics to Support Ecological Risk Assessment: A Case Study with Bisphenol A in Fish. Environ Sci Technol. 2012;46:51-9.

21. Garcia-Reyero N, Ekman DR, Habib T, Villeneuve DL, Collette TW, Bencic DC, et al. Integrated approach to explore the mechanisms of aromatase inhibition and recovery in fathead minnows (Pimephales promelas). Gen Comp Endocrinol. 2014;203:193-202.

22. Smyth GK. Limma: linear models for microarray data. In: Gentleman R, Carey V, Dudoit S, Irizarry R, Huber W, editors. Bioinformatics and Computational Biology Solutions using R and Bioconductor. New York: Springer; 2005. p. 397-420.

23. The R Project for Statistical Computing. http://www.r-project.org. Accessed July 8, 2015.

24. Zhang S-D, Gant TW. A simple and robust method for connecting small-molecule drugs using gene-expression signatures. BMC Bioinformatics. 2008;9:258.

25. Lopes CT, Franz M, Kazi F, Donaldson SL, Morris Q, Bader GD. Cytoscape Web: an interactive web-based network browser. Bioinformatics. 2010;26:2347-8.

26. NCBI-gene. ftp://ftp.ncbi.nlm.nih.gov/gene/DATA/gene2accession.gz. Accessed November 15, 2014.

27. Agilent-earray. https://earray.chem.agilent.com/earray/015064_D_AA_ 20140627.txt. Accessed Novembler 15, 2014

28. Wang R-L, Biales A, Bencic B, Lattier D, Kostich M, Villeneuve D, et al. DNA Microarray Application In Ecotoxicology: Experimental Design, Microarray Scanning, And Factors Affecting Transcriptional Profiles In A Small Fish Species. Environ Toxicol Chem. 2008;27:652-63.

29. Vidal-Dorsch D, Colli-Dula RC, Bay SM, Greenstein DJ, Wiborg L, Petschauer D, et al. Gene Expression of Fathead Minnows (Pimephales promelas) Exposed to Two Types of Treated Municipal Wastewater Effluents. Environ Sci Technol. 2013:47:11268-77.

30. Martinović-Weigelt D, Mehinto AC, Ankley GT, Denslow ND, Barber LB, Lee $\mathrm{KE}$, et al. Transcriptomic Effects-Based Monitoring for Endocrine Active Chemicals: Assessing Relative contribution of Treated Wastewater to Downstream Pollution. Environ Sci Technol. 2014;48:2385-94.

31. Lee KE, Langer SK, Barber LB, Writer JH, Ferrey ML, Schoenfuss HL et al. Endocrine active chemicals, pharmaceuticals, and other chemicals of concern in surface water, wastewater-treatment plant effluent, and bed sediment, and biological characteristics in selected streams, Minnesota design, methods, and data, 2009. USGS Data Series 575. 2011; U.S. Geological Survey, Reston, VA

32. Adamska M, Degnan SM, Green KM, Adamski M, Craigie A, Larroux C, et al. Wnt and TGF- $\beta$ expression in the sponge Amphimedon queenslandica and the origin of metazoan embryonic patterning. PLoS One. 2007. doi:10.1371/ journal.pone.0001031.
33. Martindale MQ. The evolution of metazoan axial properties. Nat Rev Genet. 2005:6:917-27.

34. Vallée M, Aiba K, Piao Y, Palin MF, Ko MS, Sirard MA. Comparative analysis of oocyte transcript profiles reveals a high degree of conservation among species. Reproduction. 2008;135:439-48.

35. Ankley GT, Johnson RD. Small fish models for identifying and assessing the effects of endocrine-disrupting chemicals. Institute Laboratory Animal Res J. 2004;45:469-83.

36. Simmons SO, Fan CY, Ramabhadran R. Cellular stress response pathway system as a sentinel ensemble in toxicological screening. Toxicol Sci. 2009; 111:202-25.

37. LaLone CA, Villeneuve DL, Burgoon LD, Russom CL, Helgen HW, Berninger JP, et al. Molecular target sequence similarity as a basis for species extrapolation to assess the ecological risk of chemicals with known modes of action. Aquat Toxicol. 2013:144-145:141-54.

38. Perkins EJ, Ankley GT, Crofton KM, Garcia-Reyero N, LaLone CA, Johnson MS, et al. Current Perspectives on the Use of Alternative Species in Human Health and Ecological Hazard Assessments. Environ Health Perspect. 2013; 121:1002-10.

39. Howe K, Clark MD, Torroja CF, Torrance J, Berthelot C, Muffato M, et al. The zebrafish reference genome sequence and its relationship to the human genome. Nature. 2013;496:498-503.

40. Chang C, Saltzman A, Yeh S, Young W, Keller E, Lee H-J, et al. Androgen Receptor: An Overview. Crit Rev Eukaryot Gene Expr. 1995;5:97-125.

41. Hall JM, Couse JF, Korach KS. The Multifaceted Mechanisms of Estradiol and Estrogen Receptor Signaling. J Biol Chem. 2001;276:36869-72.

42. Paris F, Balaguer P, Térouanne B, Servant N, Lacoste C, Cravedi JP, et al. Phenylphenols, biphenols, bisphenol-A and 4-tert-octylphenol exhibit alpha and beta estrogen activities and antiandrogen activity in reporter cell lines. Mol Cell Endocrinol. 2002:193:43-9.

43. Ekman DR, Hartig PC, Cardon M, Skelton DM, Teng Q, Durhan EJ, et al. Metabolite Profiling and a Transcriptional Activation Assay Provide Direct Evidence of Androgen Receptor Antagonism by Bisphenol A in Fish. Environ Sci Technol. 2012:46:9673-80.

44. Wilson VS, Cardon MC, Gray Jr LE, Hartig PC. Competitive binding comparison of endocrine-disrupting compounds to recombinant androgen receptor from fathead minnow, rainbow trout, and human. Environ Toxicol Chem. 2007:26:1793-802.

45. Boberg J, Taxvig C, Christiansen S, Hass U. Possible endocrine disrupting effects of parabens and their metabolites. Reprod Toxicol. 2010;30:301-12.

46. Shioda T, Rosenthal NF, Coser KR, Suto M, Phatak M, Medvedovic M, et al. Expressomal approach for comprehensive analysis and visualization of ligand sensitivities of xenoestrogen responsive genes. Proc Natl Acad Sci U S A. 2013;110:16508-13.

47. Uren Webster TM, Santos EM. Global transcriptomic profiling demonstrates induction of oxidative stress and of compensatory cellular stress responses in brown trout exposed to glyphosate and Roundup. BMC Genomics. 2015:16:32

48. Carney SA, Peterson RE, Heideman W. 2,3,7,8-Tetrachlorodibenzo-p-dioxin activation of the anyl hydrocarbon receptor/aryl hydrocarbon receptor nuclear translocator pathway causes developmental toxicity through a CYP1A independent mechanism in zebrafish. Mol Pharmacol. 2004;66:512-21.

49. Andrysík Z, Vondráček J, Marvanová S, Ciganek M, Neča J, Pěnčíková K, et al. Activation of the aryl hydrocarbon receptor is the major toxic mode of action of an organic extract of a reference urban dust particulate matter mixture: the role of polycyclic aromatic hydrocarbons. Mutat Res. 2011;714:53-62.

50. Dang ZC, Audinot V, Papapoulos SE, Boutin JA, Löwik CW. Peroxisome proliferator-activated receptor gamma (PPARgamma) as a molecular target for the soy phytoestrogen genistein. J Biol Chem. 2003;278:962-7.

51. Sengupta S, Obiorah I, Maximov PY, Curpan R, Jordan VC. Molecular mechanism of action of bisphenol and bisphenol A mediated by oestrogen receptor alpha in growth and apoptosis of breast cancer cells. $\mathrm{Br}$ J Pharmacol. 2013:169:167-78.

52. DeMayo FJ, Zhao B, Takamoto N, Tsai SY. Mechanisms of action of estrogen and progesterone. Ann N Y Acad Sci. 2002;955:48-59.

53. Werner R, Holterhus PM. Androgen action. Endocr Dev. 2014;27:28-40.

54. Creese I, Burt D, Snyder SH. Dopamine receptor binding predicts clinical and pharmocological potencies of antischizophrenic drugs. Science. 1976; 192:481-3.

55. Griffin CE, Kaye AM, Pharm D, Bueno FR, Kaye AD. Benzodiazepine Pharmacology and Central Nervous System-Mediated Effects. Ochsner J. 2013;13:214-23. 
56. Soderlund DM, Clark JM, Sheets LP, Mullin LS, Piccirillo VJ, Sargent D, et al. Mechanisms of pyrethroid neurotoxicity: implications for cumulative risk assessment. Toxicology. 2002;171:3-59.

57. Arnaud L, Taillandier G, Kaouadji M, Ravanel P, Tissut M. Photosynthesis inhibition by phenylureas: A QSAR approach. Ecotoxicol Environ Saf. 1994; 28:121-33.

58. Kim JR, Kim HJ, Kwon OS. Acetylcholinesterase and neuropathy target esterase activity in female and male rats exposed to pesticide terbufos. Environ Toxicol Pharmacol. 2005;20:149-56.

59. Soni MG, Taylor SL, Greenberg NA, Burdock GA. Evaluation of the health aspects of methyl paraben: a review of the published literature. Food Chem Toxicol. 2002;40:1335-73.

60. Matsunaka S. Activation and inactivation of herbicides by higher plants. Residue Rev. 1969;25:45-58.

61. Carrier G, Brunet RC. A toxicokinetic model to assess the risk of azinphosmethyl exposure in humans through measures of urinary elimination of alkylphosphates. Toxicol Sci. 1999:47:23-32.

62. Wang DW, Mistry AM, Kahlig KM, Kearney JA, Xiang J, George AL. Propranolol blocks cardiac and neuronal voltage-gated sodium channels. Front Pharmacol. 2010;1:144.

63. Oggier DM, Lenard A, Küry M, Hoeger B, Affolter M, Fent K. Effects of the Protein Kinase Inhibitor PKC412 on Gene Expression and Link to Physiological Effects in Zebrafish Danio rerio Eleuthero-Embryos. Toxicol Sci. 2011:119:104-15.

64. Roy A, Pahan K. Gemfibrozil, stretching arms beyond lipid lowering. Immunopharmacol Immunotoxicol. 2009:31:339-51.

65. Rodriguez-Jorquera IA, Kroll KJ, Toor GS, Denslow ND. Transcriptional and physiological response of fathead minnows (Pimephales promelas) exposed to urban waters entering into wildlife protected areas. Environ Pollut. 2015; 199:155-65.

\section{Submit your next manuscript to BioMed Central and we will help you at every step:}

- We accept pre-submission inquiries

- Our selector tool helps you to find the most relevant journal

- We provide round the clock customer support

- Convenient online submission

- Thorough peer review

- Inclusion in PubMed and all major indexing services

- Maximum visibility for your research 